\title{
Transcriptional profiling provides insights into metronomic cyclophosphamide-activated, innate immune-dependent regression of brain tumor xenografts
}

\author{
Joshua C Doloff and David J Waxman ${ }^{*}$
}

\begin{abstract}
Background: Cyclophosphamide treatment on a six-day repeating metronomic schedule induces a dramatic, innate immune cell-dependent regression of implanted gliomas. However, little is known about the underlying mechanisms whereby metronomic cyclophosphamide induces innate immune cell mobilization and recruitment, or about the role of DNA damage and cell stress response pathways in eliciting the immune responses linked to tumor regression.

Methods: Untreated and metronomic cyclophosphamide-treated human U251 glioblastoma xenografts were analyzed on human microarrays at two treatment time points to identify responsive tumor cell-specific factors and their upstream regulators. Mouse microarray analysis across two glioma models (human U251, rat 9L) was used to identify host factors and gene networks that contribute to the observed immune and tumor regression responses.

Results: Metronomic cyclophosphamide increased expression of tumor cell-derived DNA damage, cell stress, and cell death genes, which may facilitate innate immune activation. Increased expression of many host (mouse) immune networks was also seen in both tumor models, including complement components, toll-like receptors, interferons, and cytolysis pathways. Key upstream regulators activated by metronomic cyclophosphamide include members of the interferon, toll-like receptor, inflammatory response, and PPAR signaling pathways, whose activation may contribute to anti-tumor immunity. Many upstream regulators inhibited by metronomic cyclophosphamide, including hypoxia-inducible factors and MAP kinases, have glioma-promoting activity; their inhibition may contribute to the therapeutic effectiveness of the six-day repeating metronomic cyclophosphamide schedule.

Conclusions: Large numbers of responsive cytokines, chemokines and immune regulatory genes linked to innate immune cell recruitment and tumor regression were identified, as were several immunosuppressive factors that may contribute to the observed escape of some tumors from metronomic CPA-induced, immune-based regression. These factors may include useful biomarkers that facilitate discovery of clinically effective immunogenic metronomic drugs and treatment schedules, and the selection of patients most likely to be responsive to immunogenic drug scheduling.
\end{abstract}

Keywords: Immunogenic chemotherapy, Microarray, Mouse tumor models, U251 glioblastoma, Innate immunity

\footnotetext{
* Correspondence: djw@bu.edu

Department of Biology, Division of Cell and Molecular Biology, Boston University, Boston, USA
}

\section{Biomed Central}

(c) 2015 Doloff and Waxman; licensee BioMed Central. This is an Open Access article distributed under the terms of the Creative Commons Attribution License (http://creativecommons.org/licenses/by/4.0), which permits unrestricted use, distribution, and reproduction in any medium, provided the original work is properly credited. The Creative Commons Public Domain Dedication waiver (http://creativecommons.org/publicdomain/zero/1.0/) applies to the data made available in this article, unless otherwise stated. 


\section{Background}

Metronomic chemotherapy utilizes drug dosages that are lower, and are given at regular, more frequent intervals than conventional maximum tolerated dose regimens, without extended rest periods [1-4]. Clinical trials of metronomic therapy commonly use cyclophosphamide (CPA; $43 \%$ of all such trials) [5], which is typically given on a low dose daily schedule [6,7]. Low dose daily metronomic dosing has shown promise in terms of improved therapeutic activity and reduced host toxicity compared to maximum tolerated dose chemotherapy, however, large randomized trials are required to definitively establish its therapeutic advantages. Metronomic dosing is widely thought to act by an anti-angiogenic mechanism $[1,8]$, reflecting the preferential sensitivity of tumor endothelial cells to low doses of CPA and several other cytotoxics [9]. However, there is increasing evidence for important effects of metronomic chemotherapy on other tumor-associated cells, in particular immune cells $[3,10]$.

Innate immunity, rather than anti-angiogenesis, can be a key mechanism leading to major regression by metronomic chemotherapy of some large, established tumors [11], as seen in work from this laboratory in implanted brain tumor models when CPA is delivered using an intermittent (every 6-day) metronomic schedule [12-15]. Macrophages, natural killer cells and dendritic cells and other bone marrow-derived innate immune cells were increased in both 9L and U251 gliomas implanted in adaptive immune ( $\mathrm{T}$ cell and B cell)-deficient scid mice. Similar responses were achieved in immunocompetent mice, where syngeneic GL261 gliomas can be completely regressed by metronomic CPA delivered on a 6-day schedule $[12,16]$. Several cytokines and chemokines associated with mobilizing innate immune response cells $[17,18]$ were also identified in these models of metronomic CPA-induced regression, including CXCL14, IL-12 $\beta$, and CXCL12/SDF1 $\alpha$. In contrast, when the 6-day repeating metronomic CPA treatment was tested in NOD-scid-gamma mice, which unlike scid mice, have deficiencies in the innate immune system $[19,20]$, tumor growth delay with eventual stasis, but not tumor regression, was achieved [12].

Intermittent metronomic CPA treatment preferentially eliminates immunosuppressive $\mathrm{CD}_{11} \mathrm{~b}^{+} \mathrm{Gr} 1^{+}$myeloid-derived suppressor cells (MDSCs) from bone marrow and spleen of glioma-bearing mice [14]. Tumor regression in our glioma models is not, however, a secondary response to the relief of innate MDSC suppression of innate NK cells [21] or to the adaptive Treg cell-based suppression of innate and adaptive cytotoxic lymphocytes reported for other metronomic regimens [22-24]. Rather, it is a direct consequence of the mobilization of innate immune cells and their recruitment to and infiltration of the chemotherapydamaged tumors. Further supporting the essential role of the innate immune system, NK cell depletion by anti-
asialo-GM1 antibody treatment increases tumor take rates and stimulates tumor growth in various human and mouse tumor models, including allogeneic YAC-1 tumors, which do not grow without NK depletion [25], and renders the regression of implanted GL261 gliomas incomplete following metronomic CPA treatment $[12,16]$. Withdrawal of anti-asialo-GM1 antibody treatment while continuing the every 6-day metronomic CPA regimen led to repopulation of the tumors by NK cells and resumption of tumor regression [12].

The mechanisms by which metronomic CPA activates and mobilizes anti-tumor innate immune cells and then recruits them to the drug-treated tumors are unknown. These mechanisms could involve tumor cell death and DNA damage or cell stress response pathways that activate a targeted immune response resulting in tumor clearance. Further, predictive factors of response have been elusive, making it difficult to optimize the dose and frequency of metronomic drug treatment $[4,5,7,26]$ or to predict which tumors (and which patients) are likely to be responsive to immunogenic metronomic scheduling, and which ones are not [27]. To address these issues, we carried out genomewide transcriptional profiling of untreated and metronomic CPA-treated human U251 tumor xenografts using human microarrays. This enabled us to identify tumor cell-specific factors that may elicit anti-tumor innate immunity. It also allowed us to characterize in a comprehensive and unbiased manner the anti-tumor innate immune response, including immune-based signaling pathways important for activating and mobilizing a targeted immune response. We also conducted transcriptional profiling of metronomic CPA-treated rat 9L and human U251 tumor xenografts using mouse microarrays. We could thus validate metronomic CPA-responsive mouse genes whose expression was previously found to be altered in the tumor compartment [12-16], as well as identify many previously unidentified host immune factors, cell types, and signaling molecules important for immune recruitment and tumor regression. Together, these findings elucidate metronomic CPAresponsive gene networks and their upstream regulators, and provide important insights into how intermittent metronomic CPA scheduling activates potent anti-tumor innate immunity leading to prolonged tumor regression.

\section{Methods}

\section{Cell lines and reagents}

CPA monohydrate was purchased from Sigma Chemical Co. (St. Louis, MO). Fetal bovine serum (FBS) and cell culture media were purchased from Invitrogen-Life Technologies (Carlsbad, CA). Glioma cell lines were authenticated by and obtained from the following sources: human U251 glioblastoma from the Developmental Therapeutics Program Tumor Repository (National Cancer Institute, Frederick, MD), and rat 9L gliosarcoma from the Neurosurgery Tissue 
Bank (UCSF, San Francisco, CA). Cells were grown at $37^{\circ} \mathrm{C}$ in a humidified, $5 \% \mathrm{CO}_{2}$ atmosphere; U251 cells were grown in RPMI 1640 and 9L in DMEM culture medium, both of which contained 10\% FBS, 100 units $/ \mathrm{ml}$ penicillin and $100 \mu \mathrm{g} / \mathrm{ml}$ streptomycin.

\section{Tumor xenografts}

Male ICR/Fox Chase immune deficient scid mice 5-6 weeks old (24-26 g) (Taconic Farms, Germantown, NY) were housed in the Boston University Laboratory of Animal Care Facility. Animals were treated using protocols specifically reviewed for ethics and approved by the Boston University Animal Care and Use Committee. 9L cells $(4 \times$ $\left.10^{6}\right)$ or U251 cells $\left(6 \times 10^{6}\right)$ were injected s.c. on each posterior flank in $0.2 \mathrm{ml}$ serum-free DMEM using a 0.5 -inch 29 -gauge needle and a $1 \mathrm{ml}$ insulin syringe. Tumor areas (length $\times$ width) were measured twice weekly using Vernier calipers (VWR, Cat. \#62379-531) and tumor volumes were calculated based on $\mathrm{Vol}=(\pi / 6) *(\mathrm{~L} * \mathrm{~W})^{3 / 2}$. Tumors were monitored and treatment groups were normalized (each tumor volume set to 100\%) once average tumor volumes reached $\sim 500 \mathrm{~mm}^{3}$. Mice were treated with CPA monohydrate on an intermittent metronomic schedule by i.p. injection at $140 \mathrm{mg} \mathrm{CPA} / \mathrm{kg}$ body weight (BW) every 6 days [11], with the dose reported here based on the nonhydrate molecular weight of 261 . Tumor sizes and mouse body weights were measured at least twice weekly. Tumor growth rates prior to drug treatment were similar among all normalized groups. CPA-treated tumors were collected 6 days after either the $2^{\text {nd }}$ or the $3^{\text {rd }} \mathrm{CPA}$ treatment cycle (U251 tumors) or 6 days after the $4^{\text {th }}$ treatment cycle (9L tumors), i.e., treatment days 12,18 and 24, respectively. Drug-free control tumors were collected on days 6,12 , and 18 (U251) and on days 0 and 10 (9L), where day 0 is the first day of drug treatment.

\section{RNA processing and microarray analysis}

Total RNA was extracted from tumor tissue using TRIzol (Invitrogen). Only high quality RNA was used in this study, as determined by Agilent Bioanalyzer (RIN value 8 or higher using Agilent Nano-Lab Chip Kit; Agilent Technologies, Santa Clara, CA). Randomized RNA pools (two independent pools per treatment group; biological replicates) were generated for both untreated and metronomic CPAtreated tumor samples by randomly distributing tumor RNA samples into pools, with each pool comprised of the following: 7-8 untreated 9L tumor RNAs (pools JD1, JD2), 4 CPA-treated 9L tumor RNAs collected 6 days after the $4^{\text {th }}$ CPA treatment (pools JD3, JD4), 8 untreated U251 tumor RNAs (pools JD5, JD6), 6-7 CPA-treated U251 tumor RNAs collected 6 days after the $2^{\text {nd }}$ CPA injection (pools JD9, JD10), or collected 6 days after the $3^{\text {rd }}$ CPA injection (pools JD7, JD8). Each pool was prepared by combining equal amounts of RNA from each of the individual tumors comprising the pool, to give a total of $7.5 \mu \mathrm{g}$ tumor RNA. RNA concentrations were determined for each pool by Nanodrop analysis (Thermo Fisher Scientific Inc., Waltham, MA) and the RNA quality (RIN number) was reconfirmed by Bioanalyzer analysis. Tumor RNA pools were used in a total of 10 two-color, metronomic CPAtreated vs. untreated control tumor hybridization microarrays by pairing the following pools: JD1 with JD3, and JD2 with JD4 (9L tumors; comparison A); JD5 with JD9, and JD6 with JD10 (U251 tumors; comparison B); JD5 with JD7, and JD6 with JD8 (U251 tumors; comparison C). Alexa 555-labeled and Alexa 647-labeled amplified RNA samples were hybridized to Agilent Whole Mouse Genome oligonucleotide microarrays $(4 \times 44 \mathrm{~K}$ platform (version 2) (Agilent Technology; platform GPL10333, array design \#026655, containing 39,429 unique probes) for 9L tumors (comparison A, above) and U251 tumors (comparisons $\mathrm{B}$ and $\mathrm{C}$, above) to probe for changes in expression of host cell (mouse) RNAs. The same U251 tumor RNA pools (comparisons B and C, above) were also analyzed on Agilent Whole Human Genome oligonucleotide microarrays $(4 \times 44 \mathrm{~K}$ platform, version 2 ; platform GPL10332, array design \#026652, containing 34,127 unique probes) to probe for changes in expression of (human) tumor RNAs. Biological replicates were analyzed with dye swaps to eliminate dye bias, as described elsewhere [28,29], giving a total of 6 mouse arrays and 4 human arrays.

\section{Microarray data and statistical analysis}

Analysis of TIFF images of each scanned slide using Agilent's feature extraction software, calculation of linear and LOWESS normalized expression ratios and initial data analysis and $p$-value calculation using Rosetta Resolver (version 5.1, Rosetta Biosoftware, Seattle, WA) [30]) were carried out by Dr. Alan Dombkowsky at the Wayne State University microarray facility (Detroit, MI) as described $[28,31]$. The Rosetta error model provides a gene-specific estimate of error by incorporating two elements: a technologyspecific estimate of error and an error estimate derived from replicate arrays [30]. The technology-specific component utilizes an intensity-dependent model of error derived from numerous self-self hybridizations. By including the technology-specific estimate, the Rosetta error model avoids false positives that occur from under-estimation of error when a small number of replicate arrays are available, thus increasing the statistical power equivalent to that which would be obtained with at least one additional replicate. Furthermore, a log-ratio error estimate was derived in the Rosetta error model from the individual error estimates of each sample (color) used in the co-hybridization. Then, for each feature an average log ratio and associated $p$-value was obtained from replicate measurements (arrays) using the Rosetta error model error-weighted averaging method, which weighs the ratio of each sample 
inversely proportional to the variance of that sample. This gives an averaged ratio with the smallest possible error. The Rosetta error model has superior accuracy in detecting and quantifying relative gene expression when compared to other statistical methods commonly used in microarray analysis, as shown by validation with spike-in experiments [32]. The full set of normalized expression ratios and p-values is available at the Gene Expression Omnibus web site (http://www.ncbi.nlm.nih.gov/geo) as GEO series GSE60864, GSE60866, and GSE60867 (GEO SuperSeries GSE60913). For analyses, both human- and mouse array-derived gene lists were generated based on |fold change $\mid>1.5$ and pvalue $<10^{-4}$; these cutoff values balanced the need to minimize false positives while maximizing microarray signal:noise. To determine microarray probe species specificity, the complete sets of human and mouse microarray probes (60 nt each) were analyzed by BLAT [33] in comparison to human and mouse genome sequences (hg19 and mm9) and RefmRNA and mRNA sequences downloaded from the UCSC genome browser. A high degree of species specificity was apparent: $91.3 \%$ of the human microarray probes matched human RefmRNA or mRNA sequences ('match' defined as sequence identity (match score) of $\geq 50 \mathrm{nt}$ of the $60 \mathrm{nt}$ microarray probe), while only $10.2 \%$ matched mouse RNA sequences. Similarly, $90.3 \%$ of the mouse array probes matched mouse RefmRNA and mRNA sequences (match score $\geq 50 \mathrm{nt}$ ), while only $9.9 \%$ matched human RNA sequences.

\section{Gene ontology and upstream regulator analysis}

The DAVID annotation tool [34] was used to analyze sets of metronomic CPA-responsive genes identified at each time point and in each tumor model to discover functional gene clusters, based on gene ontology and other gene annotations, that show significant enrichment (enrichment score $\geq 1.3$, equivalent to $\mathrm{p} \leq 0.05$ ). The upstream pathway analysis module of Ingenuity Pathway Analysis (IPA) (Build 320386 M, Version 21249400) was used to calculate upstream regulator enrichments and to determine whether the regulators identified are either in an activated or an inhibited state [35]. Overlap p-values were calculated by IPA using Fisher's Exact Test to determine the likelihood that the putative upstream regulator is in fact an upstream regulator, based on the significance of the overlap between the known targets of each putative upstream regulator and the identified set of regulated genes. Overlap $\mathrm{p}$-values $<0.01$ are considered significant by IPA; however, we increased the stringency to $p<E-04$ to focus on those regulators with a high probability for upstream regulation. For each upstream regulator that met these cutoffs, an activation Z-score, calculated by IPA, was determined by comparing the known effect of the regulator on each target gene (activation or suppression) to the observed changes in gene expression. Based on the concordance between these patterns, an activation Zscore was assigned by IPA after correcting for cases where the regulation directions of the dataset and downstream causal edges are skewed, enabling us to infer whether a given upstream regulator was in an activated state (biascorrected Z-score $>2$ ), an inhibited state (bias-corrected Z-score $<-2$ ), or an uncertain state [35]. An overlap p-value $<$ E-04 was also applied when carrying out mechanistic network refinement within IPA. Upstream regulators that were drugs and other exogenous chemicals were excluded from further consideration and are not presented.

\section{Results}

Impact of metronomic CPA treatment on tumor cell gene expression

Microarray analysis of U251 human tumor xenografts was carried out to identify human tumor cell genes whose expression was either increased or decreased by CPA treatment on a 6-day repeating metronomic schedule. Tumor RNA samples were analyzed on treatment days 12 and 18, i.e., 6 days after the $2^{\text {nd }}$ and 6 days after the $3^{\text {rd }} \mathrm{CPA}$ injections, respectively. Day 12 represents an early time point in innate immune cell recruitment and tumor regression, while day 18 is well into the tumor regression response [12]. Tumor transcriptional profiles were assayed using human microarrays containing $~ 40,000$ probes representing 20,000 human genes. Genes showing significant increases or decreases in expression compared to drug-free controls were identified: expression of 806 genes increased at both time points while 641 genes decreased at both time points. Further, only 8 genes showed opposite regulation at day 12 vs. day 18, indicating a very high consistency of the directionality of responses between time points. Many other genes showed significant changes in expression on day 12 only, or on day 18 only. A completed listing of all regulated microarray probes, and their associated gene names and annotations, expression ratios, p-values and signal intensities is provided in Additional file 1: Table S1. Table 1 presents expression data for select examples of U251 tumor cell genes whose responses to metronomic CPA are beneficial to the overall therapeutic response, as well as genes whose responses are undesirable, e.g., induction of the tumor-promoting MMP13, the immune-inhibitory adhesion molecule CEACAM1, and the pro-metastatic factors LAMP3/CD208 and ACP5.

DAVID analysis [34] identified functional gene ontology clusters significantly enriched in the sets of U251 tumor cell-expressed genes showing a consistent pattern of increased expression at both CPA time points. Highest enrichments were found for the gene ontology clusters inflammatory/defense response, histone/nucleosome core, cytokine activity and cytokine stimulus, induction/regulation of apoptosis, and positive regulation of the (innate) immune system (Table 2A; Additional file 1: Table S2A). 
Table 1 Examples of U251 human tumor cell genes that constitute beneficial responses (A) or undesirable responses (B) to metronomic CPA treatment

\begin{tabular}{|c|c|c|c|c|c|c|}
\hline \multicolumn{7}{|c|}{ A. Beneficial responses } \\
\hline \multirow[t]{2}{*}{ Gene } & \multicolumn{2}{|l|}{ U251 (day 12) } & \multicolumn{2}{|l|}{ U251 (day 18) } & \multirow[t]{2}{*}{ Pro-tumor or Anti-tumor Activities } & \multirow[t]{2}{*}{ References } \\
\hline & Fold change & $p$-value & Fold change & $p$-value & & \\
\hline LUM & 8.7 & $1.3 E-06$ & 14.1 & 1.7E-14 & Inhibits tumor cell migration and invasion & [112] \\
\hline SSTR2 & 5.5 & $7.5 E-23$ & 5.9 & 0 & Inhibits glioma proliferation & [113] \\
\hline IFNB1 & 5.5 & $9.3 E-37$ & 5.9 & $2.5 E-43$ & $\begin{array}{l}\text { Pro-apoptotic, anti-proliferative, anti-angiogenic factor; inhibits } \\
\text { accumulation of pro-angiogenic tumor-associated neutrophils }\end{array}$ & {$[114,115]$} \\
\hline ZBP1 & 4.8 & 0 & 5.6 & 0 & $\begin{array}{l}\text { DNA sensor; activates IRFs, NFkB, and innate immunity; } \\
\text { interferon-inducible }\end{array}$ & [116-118] \\
\hline XAF1 & 2.8 & $2.2 E-35$ & 5.5 & 0 & Interferon-inducible, pro-apoptotic & [119] \\
\hline IFIT3 & 4.0 & 1.7E-37 & 5.3 & $7.8 E-42$ & Interferon-inducible, pro-apoptotic & [120] \\
\hline DMBT1 & 3.3 & 7.0E-15 & 5.0 & 0 & Tumor suppressor down-regulated in glioblastoma & [121] \\
\hline DDX58 & 2.8 & $6.5 E-43$ & 4.5 & 0 & Induces interferon-I, activates apoptosis & [122] \\
\hline TNFSF4/OX40L & 2.3 & $2.5 E-08$ & 3.5 & $2.8 E-31$ & Increases adhesion of activated T cells at tumor site & [123] \\
\hline CXCL2/MIP2 & -4.6 & $3.8 E-14$ & -3.1 & 1.3E-09 & Up-regulated in temozolomide-resistant glioma & [124] \\
\hline CXCR4 & -3.6 & 7.4E-38 & -5.0 & $2.0 E-26$ & Promotes angiogenesis in glioma & {$[125,126]$} \\
\hline LGR5 & -4.7 & $3.8 E-43$ & -5.3 & $1.2 E-39$ & Marker for poor prognosis in glioblastoma & [127] \\
\hline IL8/CXCL8 & -7.6 & $1.5 E-11$ & -5.5 & 1.1E-24 & $\begin{array}{l}\text { Proinflammatory cytokine; increases tumor angiogenesis, } \\
\text { invasion and metastasis; interferon-inducible }\end{array}$ & [128] \\
\hline \multicolumn{7}{|c|}{ B.B. Undesirable responses } \\
\hline \multirow[t]{2}{*}{ Gene } & \multicolumn{2}{|l|}{ U251 (day 12) } & \multicolumn{2}{|l|}{ U251 (day 18) } & Pro-tumor or Anti-tumor Activities & References \\
\hline & Fold change & $p$-value & Fold change & $p$-value & & \\
\hline MMP13 & 10.1 & $1.1 E-11$ & 15.4 & 0 & Promotes tumor cell proliferation and invasion & [129] \\
\hline CEACAM1 & 5.9 & 4.7E-29 & 13.2 & 7.7E-29 & Immune-inhibitory adhesion molecule; interferon-inducible & [94] \\
\hline LAMP3/CD208 & 6.4 & $1.5 E-30$ & 9.6 & 0 & Promotes metastases & [130] \\
\hline EREG & 6.5 & $2.3 E-25$ & 8.5 & 0 & Binds EGFR and induces glioma cell growth & [95] \\
\hline IDO1 & 4.8 & 0 & 6.5 & 0 & Immunosuppressive in human glioblastoma; interferon-inducible & [96] \\
\hline ACP5 & 4.5 & $2.3 E-33$ & 5.0 & $7.2 E-39$ & Pro-metastatic factor & [131] \\
\hline
\end{tabular}

Shown are fold-change values (fold increases or decreases in expression compared to drug-free controls) and associated p-values derived from microarray analyses for U251 tumors analyzed on day 12 and day 18 after initial CPA treatment.

Genes whose expression was decreased at both CPA time points were associated with extracellular signal, cell adhesion, skeletal system and blood vessel development, and extracellular matrix genes (Table 2B; Additional file 1: Table S2B). The top up-regulated gene cluster, inflammatory defense response, included several chemokines and chemokine receptors (CXCL9, CXCL10, CXCL11, CCL5, CCL26, CCR1), interleukins and interleukin receptors (IL4, IL23A, IL1R1, IL17RB, IL20RB), tumor necrosis factor ligand TNFSF4, interferon IFNB1, complement components $(C 1 Q B$, $C 1 S, C 2, C 3, C 4 B, C F B, C F H)$, peroxisome proliferatoractivated receptor PPARG, and Toll-like receptors TLR3 and TLR4.

\section{Tumor-specific pathways activated by metronomic CPA treatment}

Functional gene networks were constructed based on the sets of tumor cell genes whose expression was significantly induced or repressed by metronomic CPA treatment. One such network (Additional file 2: Figure S1), which is activated on day 12 and may contribute to the early antitumor actions of CPA, includes many intracellular cell death factors, such as $B I K$, important for mitochondrial rupture, death effector signaling caspases, DNA repair and cell death signaling poly-A ribose polymerases (PARP10 and PARP12), tumor necrosis factor TNFSF10, the $20 \mathrm{~S}$ proteasome, and several cytokeratins, including KRT18, which is released from CPA-treated tumors and is a biomarker for clinical response to therapy [36]. Genes important for extracellular presentation of cellular stresses and activating inflammatory immune responses were also induced at both early (day 12) and late (day 18) CPA treatment times. Pathways involving tumor-expressed extracellular membrane-bound chemokines CXCL9, CXCL10, and CXCL11 were identified and show potential interactions in networks translating intracellular damage to 
Table 2 Enriched clusters of gene annotation terms for U251 (human) tumor genes up-regulated (A) or down-regulated (B) by metronomic CPA treatment

\begin{tabular}{llll}
\hline Cluster name & Cluster enrichment score & $\begin{array}{l}\text { Number of genes } \\
\text { (top term) }\end{array}$ & $\begin{array}{c}\text { p-value } \\
\text { (top term) }\end{array}$ \\
\hline A. Up-regulated tumor gene clusters & & 63 & 190 \\
Inflammatory/defense response to wounding & 9.15 & 17 & $3.91 \mathrm{E}-12$ \\
Signal peptide/glycoprotein/secreted & 6.01 & 83 & $3.67 \mathrm{E}-13$ \\
Histone/nucleosome core & 5.02 & 20 & $1.00 \mathrm{E}-12$ \\
Integral plasma membrane & 4.29 & 31 & $1.29 \mathrm{E}-06$ \\
Cytokine activity & 3.38 & 21 & $7.73 \mathrm{E}-06$ \\
Induction/regulation of apoptosis & 3.26 & 29 & $6.36 \mathrm{E}-05$ \\
Response to bacterium/cytokine stimulus & 2.99 & & $1.72 \mathrm{E}-07$ \\
Positive regulation of (innate) immune system & 2.72 & 81 & $2.75 \mathrm{E}-08$ \\
B. Down-regulated tumor gene clusters & & 37 & $1.12 \mathrm{E}-04$ \\
Extracellular signal & 5.04 & 22 & $1.24 \mathrm{E}-04$ \\
Cell adhesion & 2.92 & 25 & $1.98 \mathrm{E}-05$ \\
Skeletal system development & 2.70 & 19 & $2.58 \mathrm{E}-06$ \\
Extracellular matrix & 2.61 & 17 & $8.45 \mathrm{E}-04$ \\
EGF-like & 2.58 & 2.54 & \\
Blood vessel development & & & \\
\hline
\end{tabular}

Analysis was based on genes that respond consistently after both 2 and 3 CPA/6-day treatment cycles (i.e., treatment days 12 and 18 ) at $\mid$ fold-change| $>1.5$ and $\mathrm{p}$-value $<10^{4}$. Shown are clusters with enrichment scores $>2.5$ whose top term contains $>15$ genes. Also shown is the number of genes and $\mathrm{p}$-value for the top term in each cluster. See Additional file 1: Tables S2A and S2B for a more complete listing of significant enrichment clusters and associated gene lists.

extracellular signals that may stimulate immune recruitment and tumor cell death (Figure 1A-C). CXCL10 increased almost 10 -fold over untreated controls at both time points and is centric to a network involving many interferon and innate immune response genes, including IFNB1, TLR4, and IDO1, an immunosuppressive factor (Figure 1A). CXCL11 expression increased almost 14-fold, and is tied to several chemokines important for extracellular signaling and immune activation in addition to interferon and TLR3 activation (Figure 1B). CXCL9 was also induced in the metronomic CPA-treated tumor cells in association with other extracellular immune activators: TNFSF4, MICB, interleukins IL12, IL15, IL23, and IL17RB, and interferon response genes (Figure $1 C$ ). $M I C B$ is one of two induced MHC class I and DNA damage response-associated activating ligands for the NK cell receptor NKG2D; $M I C B$ was significantly induced at both CPA time points, while a second such factor, $U L B P 2$, was up-regulated at the day 18 time point only (Additional file 1: Table S1).

\section{Upstream regulator analysis}

IPA's Upstream Regulator Analysis is a powerful way to identify putative 'master regulators' of complex gene expression changes, such as those induced by metronomic CPA treatment. This analysis is particularly important for upstream regulators that are regulated at the protein level (e.g., by phosphorylation, or by ligand binding) and therefore would not be identified by gene expression microarray analysis. We implemented this analysis 1) to identify upstream regulators of the U251 tumor genes showing consistent responses at both metronomic CPA time points, and 2) to determine whether the upstream regulators are activated or inhibited, based on the direction of CPA-induced responses of their gene targets. We thus identified several interferon signaling network members as the most significantly activated upstream regulators (IFN $\alpha$, IFN $\alpha 2$, IFN $\beta$, IFN $\gamma$, IFNL1, IRF1) (Table 3); together, these factors regulate many downstream immune response genes (Figure 2, Additional file 2: Figure S2A). Other activated upstream regulators include: TGM2 (transglutaminase 2), which is associated with glioma stem-like cells [37]; the PAF1 transcriptional complex [38]; IL27, which induces differentiation of glioma cell to astrocytes [39] and promotes anti-tumor immune responses [40] (Additional file 2: Figures S2B and S2C); growth hormone, which increases NK cell cytotoxicity to glioma cells [41]; and the endostatin precursor COL18A1. Top upstream regulators whose activity is inhibited by metronomic CPA include: MAPK1 and ERK1/2, which mediate cell proliferative signals; IL1 receptor antagonist IL1RN, which supports malignant glioma growth [42]; HIF1A (hypoxia-inducible factor-1 and EPAS1 (hypoxia-inducible factor-2 which mediate responses to hypoxia and can promote glioma growth [43]; NUPR1, which has a functional role in cancer cell resistance to conventional chemotherapeutic drugs [44]; GAPDH, which is dysregulated in several cancers, including glioma, and may promote tumor growth [45]; NEDD9, an adhesion protein that increases glioblastoma invasiveness [46]; 


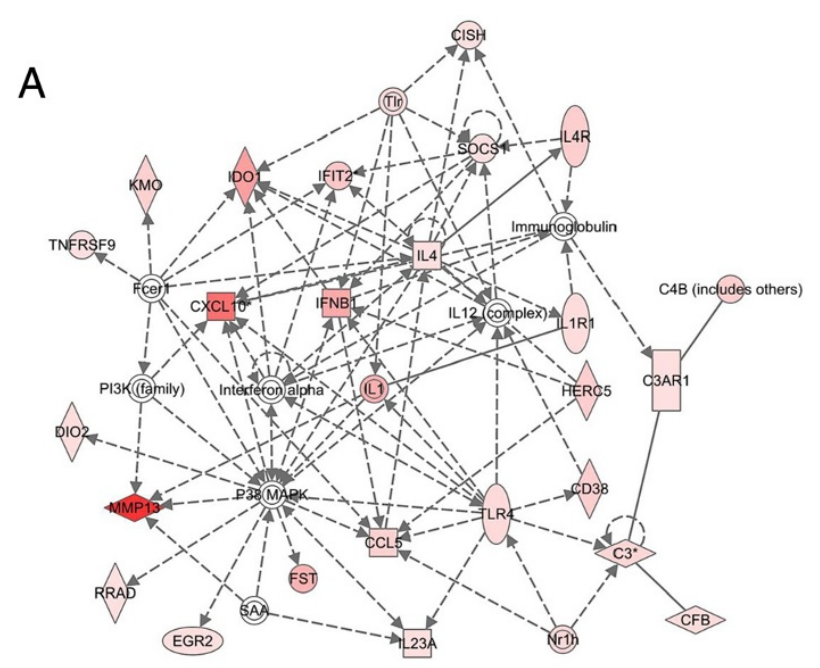

B
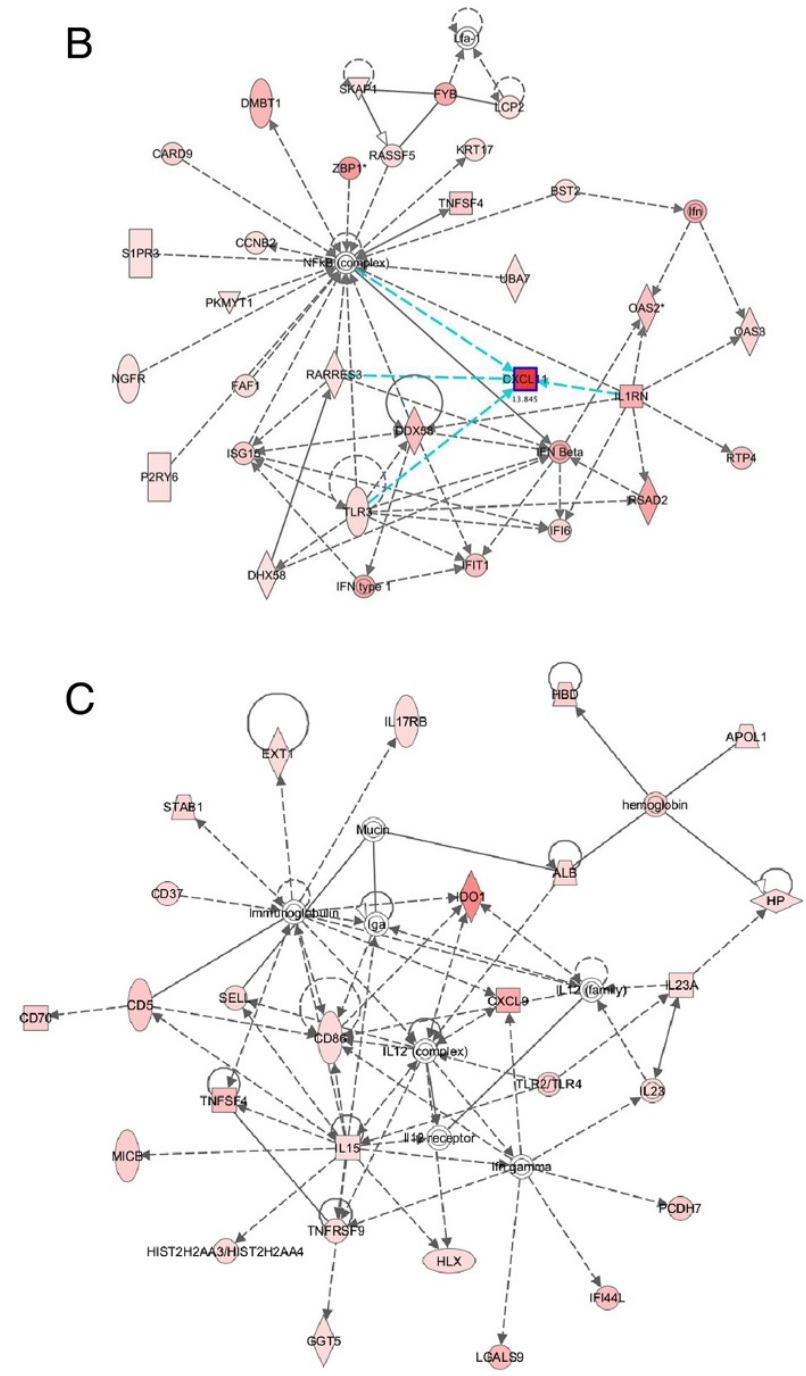

Figure 1 (See legend on next page.) 
(See figure on previous page.)

Figure 1 Top networks associated with U251 tumor human genes increased by metronomic CPA treatment on both day 12 and day 18 (late responses), as determined by IPA. A) Top network for the human chemokine CXCL10, involved in innate immune activation via toll-like receptor (TLR) and interferon (IFN) response pathways. B) Top network for the human chemokine CXCL11, involved in innate immune activation via DNA damage, TLR, IFN, and secretory chemokine/cytokine pathways. C) Top network for the human chemokine CXCL9, involved in innate immune activation via toll-like receptor, interleukin, and cell stress ligand MICB response pathways. Deeper shades of red-filled shapes indicate stronger up regulation of the gene by metronomic CPA treatment, as determined by microarray analysis. Solid arrows: protein-DNA interactions; solid lines: protein-protein; dashed arrows: regulation of gene expression; colored: related to highlighted factor(s). Shapes indicate protein family: rectangle: receptor; square: cytokine; triangle: kinase; diamond: enzyme; oval: factor (ie., transcription); concentric circles: complex; circle: other.

SOCS1, a negative regulator of cytokine signaling; MAP3K7/ TAK1, a key component of NFKB and MAP kinase signaling linked to the innate immune system [47]; RELA, which contribute to tumor cell survival and promotes inflammation in the tumor microenvironment [48]; and TGFB1, which increases glioma malignancy [49]. The inhibition of these upstream regulators, which primarily have protumor functions, is consistent with the therapeutic effectiveness of metronomic CPA in this glioma model. Other upstream regulators did not exhibit a clear pattern of activation or inhibition (Additional file 1: Table S3).

\section{Characterization of host (mouse) gene responses linked} to immune cell activation and tumor infiltration

Next, we used mouse microarrays to investigate the extent of host (mouse) immune cell involvement in the

Table 3 Upstream regulators of metronomic CPA-responsive human genes

\begin{tabular}{|c|c|c|c|}
\hline Upstream regulator & Molecule type & p-value of overlap & \# of \\
\hline \multicolumn{4}{|c|}{ A. Activated upstream regulators (human gene targets) } \\
\hline IFNL1/IL29 & Cytokine & $1.72 \mathrm{E}-29$ & 36 \\
\hline IFNG & Cytokine & $5.04 \mathrm{E}-23$ & 68 \\
\hline IFNA2 & Cytokine & $8.87 \mathrm{E}-23$ & 36 \\
\hline TGM2 & Enzyme & $6.30 \mathrm{E}-14$ & 43 \\
\hline IFNB1 & Cytokine & $7.98 \mathrm{E}-10$ & 14 \\
\hline Interferon alpha & Cytokine & $1.57 \mathrm{E}-07$ & 23 \\
\hline PAF1 & Transcription complex & $1.89 \mathrm{E}-07$ & 14 \\
\hline IRF1 & Transcription regulator & $1.25 \mathrm{E}-06$ & 12 \\
\hline IL27 & Cytokine & 1.65E-06 & 14 \\
\hline Growth hormone & Protein hormone & $1.37 \mathrm{E}-05$ & 12 \\
\hline COL18A1 & Endostatin precursor & $9.08 \mathrm{E}-05$ & 13 \\
\hline \multicolumn{4}{|c|}{ B. Inhibited upstream regulators (human gene targets) } \\
\hline MAPK1 & Kinase & $4.88 \mathrm{E}-30$ & 57 \\
\hline IL1RN & Cytokine & $2.26 \mathrm{E}-15$ & 26 \\
\hline HIF1A & Transcription regulator & $1.09 \mathrm{E}-14$ & 40 \\
\hline EPAS1 & Transcription regulator & $6.48 \mathrm{E}-12$ & 24 \\
\hline NUPR1 & Transcription regulator & $3.60 \mathrm{E}-11$ & 68 \\
\hline GAPDH & Enzyme & $2.75 \mathrm{E}-10$ & 14 \\
\hline NEDD9 & Cell adhesion protein & $2.34 \mathrm{E}-08$ & 13 \\
\hline SOCS1 & Cytokine signaling inhibitor & $6.93 \mathrm{E}-08$ & 12 \\
\hline MAP3К7/ТАK1 & Kinase & $1.05 \mathrm{E}-07$ & 12 \\
\hline ERK1/2 & Kinase & $1.47 \mathrm{E}-07$ & 22 \\
\hline RELA & Transcription regulator & $4.72 \mathrm{E}-07$ & 24 \\
\hline TGFB1 & Growth factor & 6.69E-06 & 37 \\
\hline
\end{tabular}

Regulators were identified by IPA of the set of U251 human tumor cell genes up-regulated or down-regulated by metronomic CPA in common at both the day 12 and day 18 times points. Shown are the upstream regulators whose activation state is reliably predicated to be activated (A) or inhibited (B) by CPA treatment, based on a bias-corrected $\mid \mathrm{Z}$-score $\mid>2$, and that meet the stringent threshold for overlap with the target gene set at $\mathrm{p}<\mathrm{E}-04$ and contain a minimum of 10 target genes in the regulated gene set. More complete information, including Z-scores, lists of target genes for each regulator, associated mechanistic networks, and other upstream regulators are shown in Additional file 1: Table S3. 


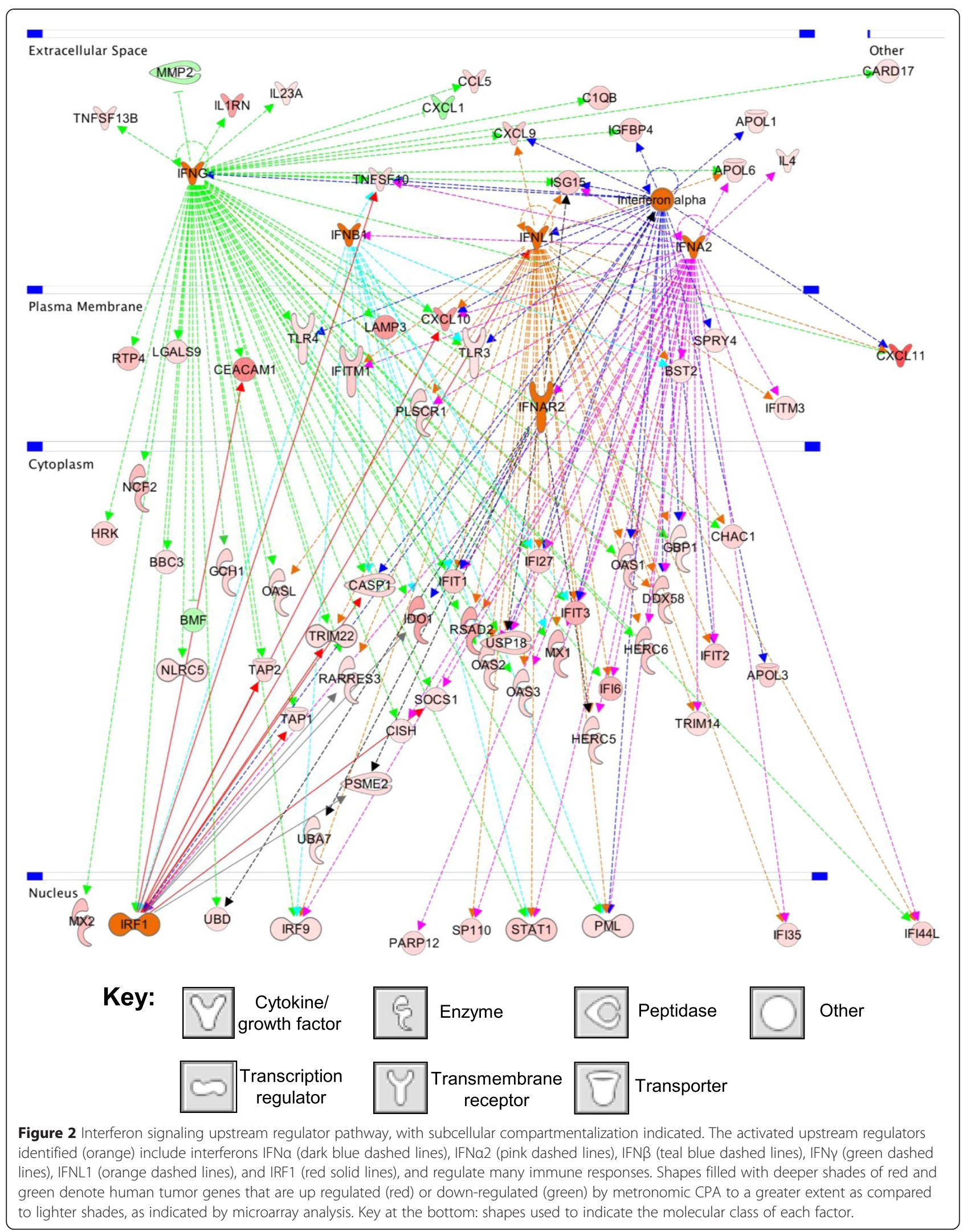


response to metronomic CPA treatment. We analyzed mouse gene responses in U251 tumors at the same two time points analyzed on the human microarrays, and additionally, at a single time point in a rat 9L glioma model, where the innate immune response to metronomic CPA is very similar to that of U251 gliomas, but requires 1-2 additional CPA injections until robust immune cell recruitment and tumor regression become apparent [12]. Metronomic CPA treatment induced 326 mouse genes and repressed 288 mouse genes in common on all three microarrays. The consistent regulation of these 614 mouse genes in both tumor models/at all three time points indicates they are robust responses (see Additional file 1: Table S4 for full listing). Large numbers of other mouse genes were late responding genes, i.e., they did not respond to metronomic CPA until the second U251 time point (treatment day 18) and also responded significantly in 9L tumors on treatment day 24 (833 up-regulated, 823 down-regulated genes). Only 8 mouse genes showed inconsistent (i.e., opposite) patterns of regulation between the two U251 time points.

Mouse genes up-regulated in both tumor models (9L, and at least one of the U251 tumor time points) were enriched in gene clusters that include the following: immune response, lysosome, regulation of cytokine production, lectin/carbohydrate binding, cytokine receptor interaction, induction of programmed cell death, leukocyte activation, and regulation of immune effector process (Table 4A). The up-regulated gene cluster showing the second highest enrichment, immune response, includes many complement genes (C1qa, C1qb, C1qc, C1ra, C2, Cfb, Cfd, Cfp), chemokines (Ccl19, Ccl24, Ccl25, Ccl3, Ccl4, Ccl6, Ccl9, Cxcl14), toll-like receptors (Tlr1, Tlr4, Tlr7, Tlr8, Tlr13), cell death effectors that act via apoptosis (Fas receptor ligand, Fasl, and tumor necrosis factor Tnfsf4 and other family members and receptors (Tnfsf10, Tnfrsf $13 c$, Tnfrsf17)), cytolysis (lysozymes 1 and 2, Lyz1 and Lyz2), and proteolytic enzyme degradation (Ctsa, Ctsb, Ctsd, Ctsh,

Table 4 Enriched clusters of gene annotation terms for host (mouse) genes up-regulated (A) or-down-regulated (B) by metronomic CPA treatment in both U251 and $9 \mathrm{~L}$ tumors

\begin{tabular}{|c|c|c|c|}
\hline Cluster name & Cluster enrichment score & $\begin{array}{l}\text { Number of genes } \\
\text { (top term) }\end{array}$ & $\begin{array}{l}\text { p-value } \\
\text { (top term) }\end{array}$ \\
\hline \multicolumn{4}{|l|}{ A. Up-regulated mouse gene clusters } \\
\hline Glycoprotein & 23.1 & 342 & $5.16 \mathrm{E}-37$ \\
\hline Immune response & 13.7 & 87 & $1.11 \mathrm{E}-26$ \\
\hline Cell surface & 8.80 & 53 & 8.91E-14 \\
\hline Lysosome & 7.38 & 31 & 2.29E-08 \\
\hline Extracellular membrane & 6.77 & 191 & 4.07E-12 \\
\hline Regulation of cytokine production & 6.44 & 28 & $9.78 \mathrm{E}-10$ \\
\hline Carbohydrate binding & 5.64 & 41 & 5.09E-08 \\
\hline Positive regulation of immune system process & 4.69 & 41 & 8.70E-14 \\
\hline Cytokine-cytokine receptor interaction & 4.10 & 36 & 1.79E-07 \\
\hline Lipid catabolic process & 3.60 & 23 & 7.60E-07 \\
\hline Induction of programmed cell death & 3.24 & 24 & $9.43 \mathrm{E}-06$ \\
\hline Cell/leukocyte activation & 3.22 & 35 & $6.63 \mathrm{E}-08$ \\
\hline \multicolumn{4}{|l|}{ B. Down-regulated mouse gene clusters } \\
\hline (Positive) regulation of transcription & 10.3 & 71 & $1.06 \mathrm{E}-13$ \\
\hline Cell division & 9.31 & 44 & 4.73E-13 \\
\hline Repressor, negative regulation of gene expression & 5.57 & 43 & 5.73E-08 \\
\hline Cell migration & 4.81 & 28 & $6.05 \mathrm{E}-06$ \\
\hline Spindle & 4.58 & 20 & $1.22 \mathrm{E}-07$ \\
\hline Skeletal system development & 4.30 & 32 & $2.56 \mathrm{E}-06$ \\
\hline Tube development & 4.09 & 29 & 1.27E-05 \\
\hline Transcription factor complex & 3.80 & 27 & $5.88 \mathrm{E}-06$ \\
\hline Microtubule cytoskeleton organization & 3.46 & 16 & $9.14 \mathrm{E}-05$ \\
\hline Sequence-specific DNA binding/Homeodomain & 3.04 & 52 & 4.54E-07 \\
\hline
\end{tabular}

Analysis was based on genes that respond to metronomic CPA treatment cycles at $\mid$ fold-change $>1.5$ and p-value $<10^{4}$ at either, or both U251 treatment time points, and also in $9 \mathrm{~L}$ tumors. Shown are clusters with enrichment scores $>3.0$ whose top term contains $>15$ genes. Also shown is the number of genes and $p$-value for the top term in each cluster. See Additional files 1: Table S5A and S5B for a more complete listing of significant enrichment clusters and associated gene lists. 


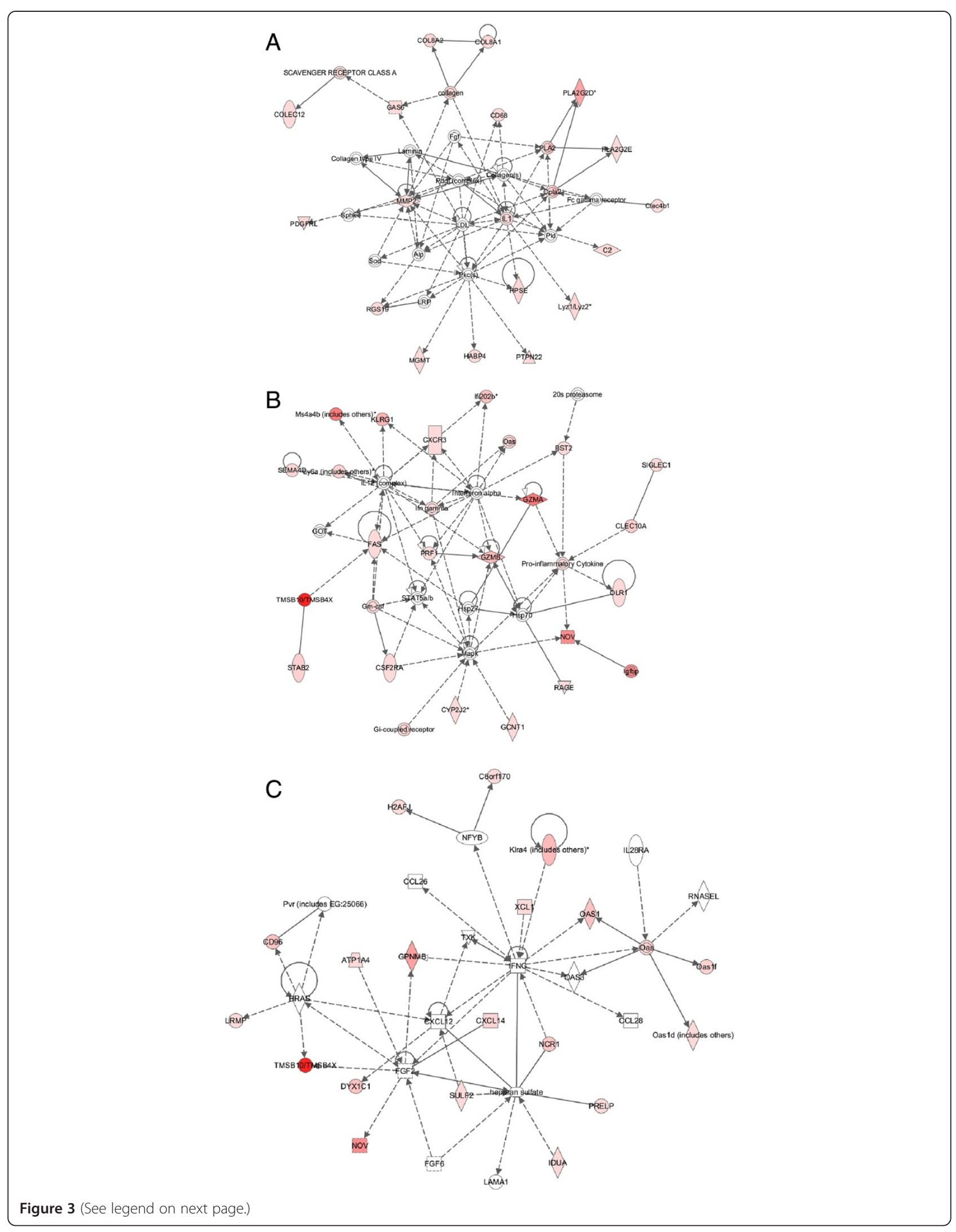


(See figure on previous page.)

Figure 3 Top networks associated with mouse (host) genes induced by metronomic CPA treatment, as determined by IPA. A) Top network showing connections between metronomic CPA-induced expression of innate immunological disease (many macrophage-related), adhesion, infiltration, scavenger, and cytolysis genes. B) Top networks for NK cell-related innate immune function: tumoricidal and infectious disease NK function, targeting via CXCR3 and FAS, and cytolysis via granzyme and perforin, and C), NK cell-related inflammatory disease network. Deeper shades of red indicate stronger up regulation of the gene by metronomic CPA treatment. Solid arrows: protein-DNA interactions; solid lines: protein-protein; dashed arrows: regulation of gene expression; colored: related to highlighted factor(s). Shapes indicate protein family: rectangle: receptor; square: cytokine; triangle: kinase; diamond: enzyme; oval: factor (i.e., transcription); concentric circles: complex; circle: other.

Ctss). Mouse genes that were down-regulated by metronomic CPA treatment were enriched for essential cellular functions, including DNA binding and transcription, cell division, cell migration, tube/epithelium development, and cytoskeleton organization (Table 4B). A complete listing of significant gene clusters is presented in Additional file 1: Tables S5A and S5B.

\section{Host immune system-related pathways activated by metronomic CPA}

We used IPA to construct functional networks of host (mouse) genes whose expression was significantly altered by metronomic CPA treatment. Several of the networks centered on immune cell function. One network highlighted immunological disease factors, many of which are macrophage-associated, including macrophage marker Cd68, scavenger receptor class A molecules (i.e., Colec12), macrophage effector lysozymes 1 and 2 (Lyz1 and Lyz2), inflammatory response phospholipases (Pla2, Pla2g2d, Pla2g2e, Cpla2), macrophage-produced lymphocyte mitogen $I l 1$, receptor responsiveness factor Ptpn22, phagocytosis regulator Gas6, and the pro-infiltration extracellular matrix remodeling enzymes Hpse and $\mathrm{Mmp} 2$ (Figure 3A). Two other networks grouped NK cell-related genes. The first network shows tumoricidal and infectious diseaserelated NK factors, including granzymes A and B (Gzma, Gzmb), perforin (Prf1), Fas death receptor (Fas), Fasmediated apoptosis gene Olr1, NK cell-expressed chemokine receptor $\mathrm{Cxcr} 3$ (the known interacting receptor for chemokines CXCL9, CXCL10, and CXCL11), MHC class I regulated NK marker Klrg1, interferon-activated genes (Ifi202b, Oas1), NK cell-expressed Ly6a and Sema4d, and lymphocyte-homing factors Stab2 and Nov (Figure 3B and Figure $3 \mathrm{C}$ ). The second network displays inflammatory disease NK cell markers NKp46 (Ncr1), migration factors Cxcl14 and Xcl1, NK perforin cytotoxicity regulator Klra4, and NK adhesion molecules (Prelp, Cd96) (Figure 3B and Figure 3C).

\section{Upstream regulators of metronomic CPA-induced anti-tumor immunity}

We analyzed the metronomic CPA-responsive mouse (host) gene sets to elucidate potential upstream regulators, including transcription factors and cytokines that may regulate anti-tumor innate immunity induced by metronomic CPA treatment. The transcription factors
PPARA, PPARG, NR1H3/LXR $\alpha$ and NR1H2/LXR $\beta$ were prominent as upstream regulators of mouse genes that respond to metronomic CPA early, i.e., 6 days after the $2^{\text {nd }}$ CPA cycle in the U251 model (Additional file 1: Table S6 and Additional file 2: Figure S3). PPARG agonists exhibit anticancer activity in glioma models [50], and increases in PPAR function have been implicated in persistent inflammation [51], while agonists of LXR promote glioblastoma cell death [52]. Upstream regulators inhibited at the same early time point include CSF2, which supports M1 macrophage polarization [53], and CD38, whose loss attenuates glioma progression $[54,55]$ (Additional file 1: Table S6). When all mouse genes showing concordance in both tumor models at the time when CPA-induced tumor regression is well underway (i.e., treatment day 18 in U251 tumors and day 24 in 9L tumors) were considered, many more upstream regulators were identified (Table 5; Additional file 1: Table S7). The activated upstream regulators include factors related to inflammatory responses (IL6, the NF B-activating kinase IKBKB, NLRP3 inflammasome, and mir-223), interferon signaling and action (IFNAR, IFNG, IFN $\alpha /$ IFN $\beta$, STAT1, IRF3, IRF5, IRF7), and TLR signaling associated with innate immune responses (TLR3, TLR4, TLR9, TICAM1, DDX58, MYD88) (Figures 4, 5, and Additional file 2: Figures S4 and S5). Other upstream regulators of the responding mouse genes include: IL12 and IL18, which stimulate macrophages and NK cells to produce IFNY and induce glioma cell death [56]; NFATC2, which is important for inducing gene transcription during an immune response; DOCK8, required for NK cell function [57]; SASH1, whose increased expression has been related to inhibition of U251 glioma cell growth, proliferation, and invasion [58]; NOS2, a marker for M1 (anti-tumor) macrophages; BNIP3L, a pro-apoptotic factor [59]; SPI1, important for myeloid cell development an innate immunity [60]; and FADD, which is recruited to activated cell death receptors [61]. These activated upstream regulators can be considered as contributing to the antitumor actions of metronomic CPA. By contrast, another activated upstream regulator, SAMSN1, which is highly expressed in glioblastoma, is associated with poor prognosis for survival [62]. SAMSN1 has also been shown to suppress B cell activation [63]. However, we previously observed no B cell involvement in our immune competent C57BL/6, 
Table 5 Upstream regulators of metronomic CPA-responsive mouse genes

\begin{tabular}{|c|c|c|c|}
\hline Upstream regulator & Molecule type & p-value of overlap & \# of target genes \\
\hline \multicolumn{4}{|c|}{ A. Activated upstream regulators (mouse gene targets) } \\
\hline IFNAR & Interferon receptor & $5.34 \mathrm{E}-14$ & 31 \\
\hline IRF3 & Transcription regulator & $5.62 \mathrm{E}-12$ & 28 \\
\hline IFNG & Interferon & $2.55 \mathrm{E}-11$ & 80 \\
\hline IL12 (complex) & Cytokine & $1.04 \mathrm{E}-10$ & 24 \\
\hline STAT1 & Transcription regulator & $1.32 \mathrm{E}-10$ & 37 \\
\hline IRF7 & Transcription regulator & $1.64 \mathrm{E}-10$ & 23 \\
\hline IFN alpha/beta & Interferon & 3.98E-09 & 20 \\
\hline NFATC2 & Transcription regulator & 4.77E-09 & 26 \\
\hline IFNB1 & Cytokine & 9.37E-09 & 34 \\
\hline TLR4 & Toll-like receptor & $3.19 \mathrm{E}-08$ & 42 \\
\hline DOCK8 & other & $4.22 \mathrm{E}-08$ & 21 \\
\hline SASH1 & other & 7.34E-08 & 21 \\
\hline TICAM1 & Adapter for TLR3 & $1.05 \mathrm{E}-07$ & 28 \\
\hline ITK & Kinase & $1.52 \mathrm{E}-07$ & 22 \\
\hline SAMSN1 & other & $2.20 \mathrm{E}-07$ & 23 \\
\hline mir-223 & MicroRNA & 3.67E-07 & 24 \\
\hline DDX58 & Enzyme & $1.15 \mathrm{E}-06$ & 14 \\
\hline IL6 & Interleukin 6 & $1.22 \mathrm{E}-06$ & 30 \\
\hline SPI1 & Transcription regulator & $1.31 \mathrm{E}-06$ & 19 \\
\hline IKBKB & Kinase that activates REL/NF B & $3.41 \mathrm{E}-06$ & 31 \\
\hline NOS2 & Nitric oxide synthase; M1 macrophage marker & $3.83 \mathrm{E}-06$ & 30 \\
\hline MYD88 & Adapter for TLRs & 7.34E-06 & 32 \\
\hline TLR3 & Transmembrane receptor & $8.10 \mathrm{E}-06$ & 27 \\
\hline BNIP3L & Pro-apoptotic factor & 9.69E-06 & 15 \\
\hline TLR9 & Transmembrane receptor & $1.33 \mathrm{E}-05$ & 25 \\
\hline NLRP3 & Inflammasome & $1.59 \mathrm{E}-05$ & 15 \\
\hline IRF5 & Transcription regulator & $2.22 \mathrm{E}-05$ & 12 \\
\hline PPARG & Ligand-dependent nuclear receptor & $5.21 \mathrm{E}-05$ & 40 \\
\hline IL18 & Cytokine & $6.86 \mathrm{E}-05$ & 11 \\
\hline FADD & Transmembrane receptor adapter protein & 7.33E-05 & 15 \\
\hline CD44 & Enzyme & 7.53E-05 & 22 \\
\hline CDKN2A & Transcription regulator & $8.10 \mathrm{E}-05$ & 20 \\
\hline \multicolumn{4}{|c|}{ B. Inhibited upstream regulators (mouse gene targets) } \\
\hline CSF2/GM-CSF & Cytokine & $3.82 \mathrm{E}-15$ & 45 \\
\hline TRIM24 & Transcription regulator & $8.10 \mathrm{E}-13$ & 32 \\
\hline PTGER2 & G-protein coupled receptor & $1.65 \mathrm{E}-09$ & 26 \\
\hline DNASE2 & Enzyme & 4.26E-08 & 14 \\
\hline ACKR2 & G-protein coupled receptor & 4.87E-08 & 15 \\
\hline sOCS1 & other & $1.26 \mathrm{E}-07$ & 20 \\
\hline mir-21 & MicroRNA & $1.67 \mathrm{E}-06$ & 25 \\
\hline TGFB1 & Growth factor & 9.61E-06 & 19 \\
\hline MYC & Transcription regulator & $1.46 \mathrm{E}-05$ & 24 \\
\hline
\end{tabular}

Upstream regulators were identified by IPA analysis of the set of mouse genes up-regulated or down-regulated by metronomic CPA in common in U251 tumors after three metronomic CPA treatments (day 18) and in 9L tumors after four metronomic CPA treatments (day 24), as described in Methods. Shown are the upstream regulators whose activation state is reliably predicated to be activated (A) or inhibited (B) by CPA treatment, with other details as described in Table 3 . More complete information, including Z-scores, lists of target genes for each regulator, associated mechanistic networks, and other upstream regulators are shown in Additional file 1 : Table S7. 


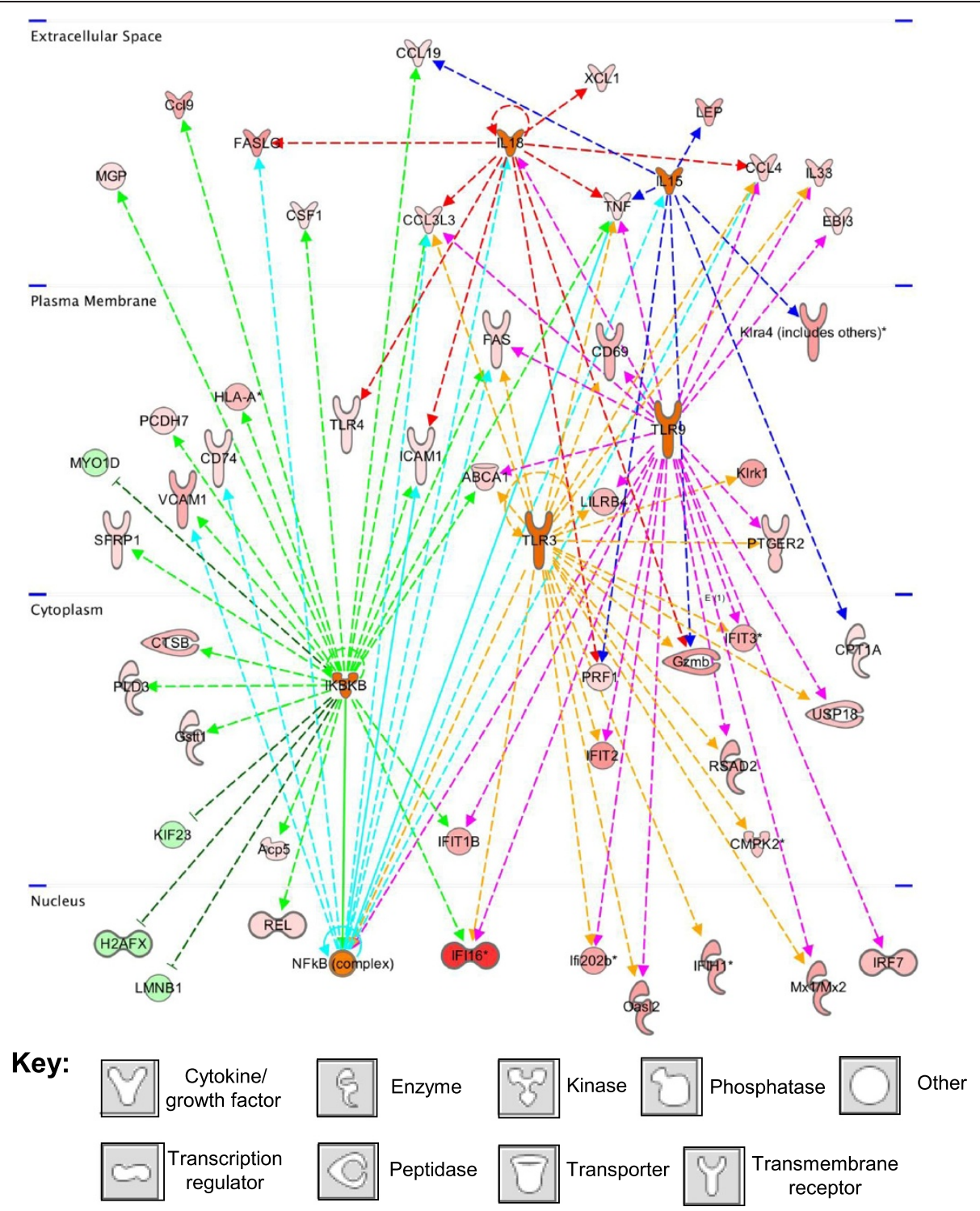

Figure 4 Downstream target network for the predicted upstream regulators of the mouse genes IL15 (dashed dark blue lines), IL18 (dashed red lines), TLR3 (dashed gold lines), TLR9 (dashed magenta lines), IKBKB (dashed green lines), and NFKB (dashed teal lines), showing multi-layer cell signaling and cross-talk between regulators, as well as downstream signaling and up- or down-regulation of genes identified on the mouse array as being responsive to metronomic CPA treatment. Genes and upstream regulators shown are only those that are common across tumor models at both late time points (U251 tumors on day 18 and 9L tumors on day 24). This network identifies potential signaling in tumor cell death-induced pathways, such as interferon, cytokine, tumor necrosis factor, TLR, and NFkB signaling. Deeper shades of red and green denote human tumor genes that are up-regulated (red) or down-regulated (green) by metronomic CPA to a greater extent as compared to lighter shades, as indicated by microarray analysis. Key at the bottom: shapes used to indicate the molecular class of each factor, as defined in Figure 3.

syngeneic GL261 glioma model [12]. Mouse upstream regulators inhibited by metronomic CPA in both tumor models include: CSF2 (GM-CSF), which induces differentiation of brain macrophages into M1 anti-tumor macrophages [64], but has also been shown to be neuroprotective [65], and perhaps its down-regulation is important for tumor ablation in these brain tumor models; TRIM24, which promotes glioma progression and enhances chemoresistance [66]; DNASE2; G-protein coupled receptors PTGER2 and ACKR2; SOCS1, an inhibitor of cytokine signaling; the oncomir mir-21; growth factor TGFB; and the oncogene Myc.

\section{Discussion}

Chemotherapy given as a single dose can stimulate antitumor immune responses, but this finding has not translated well to the cancer clinic, where many conventional chemotherapy regimens are toxic to T cells, NK cells and 


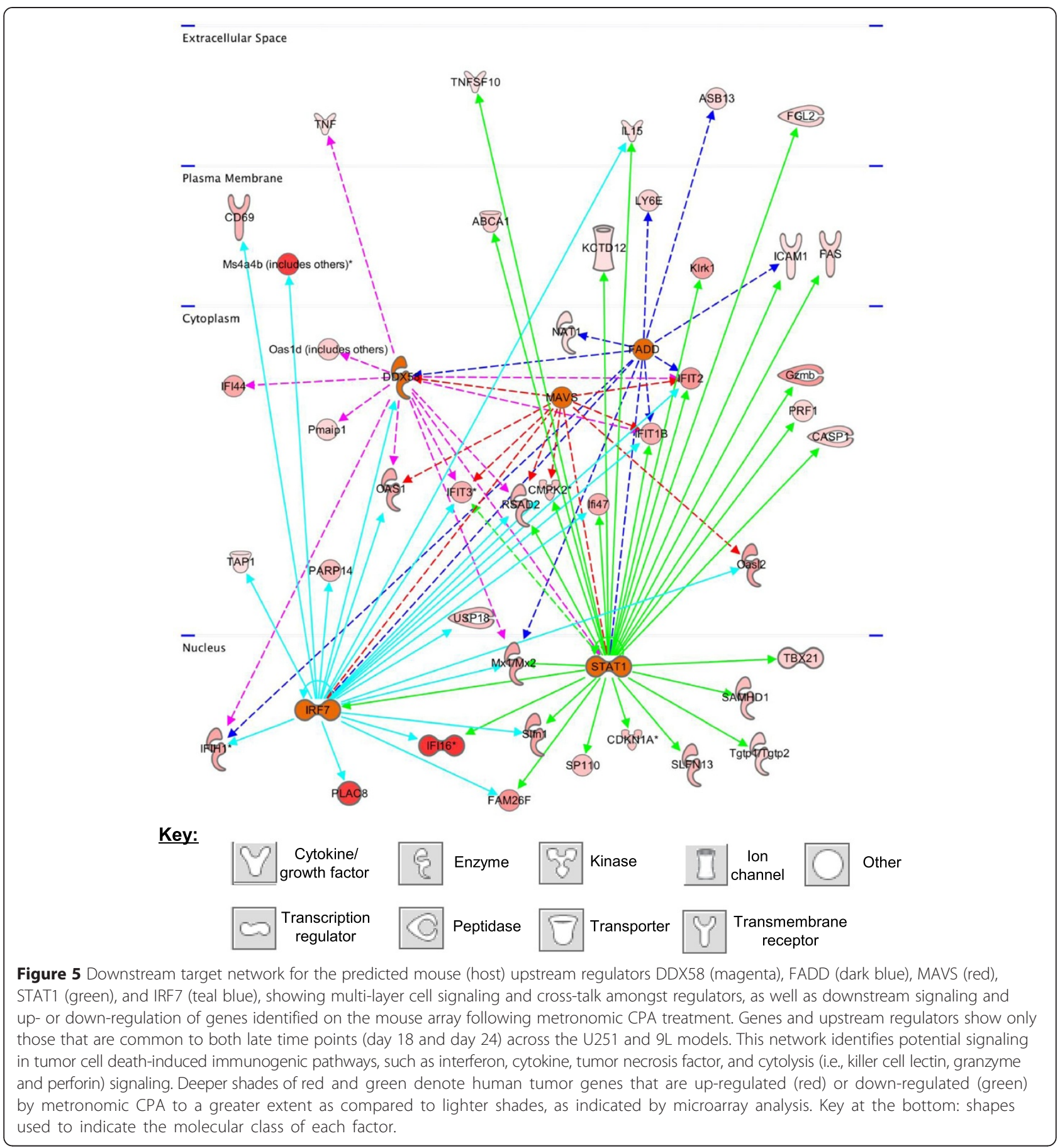

dendritic cells, leading to immunosuppression $[67,68]$. Recent studies from this laboratory have shown that administration of CPA on a metronomic, 6-day repeating schedule activates a potent anti-tumor response in several implanted glioma models leading to major regression of large tumors that is dependent on innate [12-15] as well as adaptive $[12,16]$ immune cells. This strong therapeutic response may involve immunogenic cell death, which can be activated by CPA and several other cytotoxic anti- cancer drugs [69,70]. Here, we conducted genome-wide transcriptional profiling of implanted U251 human glioblastoma and 9L rat gliosarcoma to further characterize this response and to obtain novel insights that help elucidate the mechanisms by which metronomic CPA activates innate anti-tumor immunity.

Several of the mouse (host) gene clusters that were either activated or repressed in the tumor compartment by metronomic CPA treatment (Table 4) are similar to 
those found in bone marrow and spleen of tumor-bearing mice when a single CPA injection was combined with adoptive cell transfer of lymphomonocytes from tumorvaccinated syngeneic mice [71]. Maximal anti-tumor activity against metastatic Friend leukemia 3CL-8 cells was seen when lymphomonocytes derived from spleens of the tumor-immunized mice where transferred within $24 \mathrm{hr}$ after a single CPA injection, with efficacy being lost when cells were transferred after $48 \mathrm{hr}$. The authors reported a "cytokine storm" in bone marrow, and to a lesser extent in spleen and in peripheral blood mononuclear cells of the CPA-treated mice, which may contribute to the observed anti-tumor response. In the present study, we characterize the potent immune stimulatory actions of CPA in the tumor compartment of two glioma models, where intermittent administration of CPA on a 6 day repeating metronomic schedule is sufficient to activate and mobilize the host immune system, resulting in potent anti-tumor activity and major tumor regression without the need for combination with adoptive immunotherapy or immunomodulatory agents.

The present study validates our previous findings that metronomic CPA recruits and/or induces many innate immune cell factors, as seen both at the level of RNA and protein in the CPA-treated tumors [12-16]. These include the death receptor Fas, which stimulates macrophage activation [72,73] and acts as an important mediator of interactions between NK cells and cells marked for destruction [74]. Macrophage marker CD68, platelet marker PF4, dendritic cell markers CD74, implicated in DC migration [75], and CD209 (DC-SIGN), important for antigen presentation, were also increased, as were NK cell markers NKp46 (Ncr1) and NK1.1 (Klrb1), NK activating receptor NKG2D (Klrk1), NK effector granzymes $\mathrm{A}$ and $\mathrm{B}$, and perforin, which are essential for cytotoxic lymphocyte-mediated cell death [76]. Cytokine and chemokine immune attractants CXCL14, IL12 $\beta$ and CXCL12/SDF1 $\alpha$ were also increased by metronomic CPA treatment, implicating chemokine and cytokine gradients in stimulating leukocyte and lymphocyte migration $[17,18]$. These targets were all validated by host (mouse) microarray analysis and shown to be upregulated by metronomic CPA in both $\mathrm{U} 251$ and 9L gliomas.

The present study also identified many additional genes and pathways that can contribute to the strong immune response activated by metronomic CPA treatment. Factors involved in immune-mediated cytolysis were identified, including the macrophage cytolytic effectors lysozymes 1 and 2 (Lyz1 and Lyz2) [77], corroborated in a recent study from our group [14], as well as several other NK cell effector granzymes [74] not investigated in our earlier studies of metronomic CPA treated-gliomas. Many additional macrophage-related genes were increased in the metronomic CPA-treated tumors (Figure 3A), supporting macrophage involvement in metronomic CPA-induced tumor regression. These include Col8A1 and Col8A2, collagen factors important for macrophage adhesion, and macrophage-associated phospholipases (Pla2g2d, Pnpla2), which are inducible by inflammation-induced interferonsecretion [78]. Other factors induced in the treated gliomas include scavenger receptor Colec12, which is important in host defense responses, matrix metalloproteinase-2 (Mmp2) and heparanase (Hpse), important for extracellular matrix remodeling and macrophage infiltration [79], Ptpn22, a phosphatase important for macrophage responsiveness, and Gas6, which regulates macrophage phagocytosis (Figure 3A). Other NK cell markers increased in the metronomic CPA-treated tumors include Ly6a, Sema4d (Cd100), Klrg1, an inhibitory NK cell receptor associated with memory NK cells [80], Stab2, which is important for lymphocyte homing and cell adhesion [81], the NK adhesion ligand $C d 96$ [82], and regulators of NK cytotoxicity, such as Sh2d1a and Klra5 [83,84] (Figure 3B and Figure 3C). Innate immune cell-associated genes Tmsb10 and Tmsb4x, which are important for cell migration and adhesion, were strongly induced (Figure 3B, left and right). Coagulation factor 3 (F3), which may contribute to an immune-mediated inflammation response [85], was also significantly up-regulated in the metronomic CPA-treated tumors. Further, $\mathrm{C} 3$ and other complement components were significantly increased by metronomic CPA treatment in both tumor models (Additional file 2: Figure S7) and likely contribute to the observed innate immune activation and clearance of dying tumor cells [86]. Another induced complement factor, Clq, is synthesized by monocytederived macrophages and dendritic cells and is important for opsonization and forming membrane lytic complexes [87], and perhaps is employed to clear CPA-damaged tumor cells. Finally, many factors related to immune-mediated proteolysis and cell death, such as $\mathrm{C} 1$-esterase inhibitor (Serping1), lymphotoxin A (TNF $\beta, L t a)$, and lymphocyte cytosolic protein 2 ( $L c p 2$ ), were identified as late responding mouse genes in the U251 and 9L models, while several cathepsins (Cts genes) were increased both at early and at late time points in both tumor models.

Upstream regulator analysis identified several type I and type II interferon signaling network members as being activated and most significantly associated with gene responses to metronomic CPA treatment (Tables 3 and 5). Many gene expression changes in the tumor compartment were thus linked to interferon signaling pathways (Figure 2, Additional file 2: Figure S6A and S6B) [88]. Examples include interferon-activated genes (Oas, Oas1, Gpnmb), genes associated with interferon-induced immune-mediated apoptosis of target cells (Olr1, Pml, Fas, Fasl) [89], and many interleukins, chemokines and cytokines involved in inflammation-based immune activation, proliferation, and 
mobilization, including colony stimulating factor 1 (Csf1), Ccl family members, Xcl1, interleukins 15 and 18 (IL15, IL18), and interferon-1, whose secretion can potentiate IL15 expression (Additional file 2: Figure S6B). Interferons exert many immune regulatory functions and can enhance the anti-tumor activity of CPA [90]. Upstream regulators of the tumor-associated mouse genes significantly altered by metronomic CPA treatment include DDX58, as well as FADD and MAVS. DDX58 is a pattern recognition receptor [91] that signals through FADD and MAVS (Figure 5) and may contribute to the observed anti-tumor immune responses. FADD is important for innate immune-based host defense [92] and signals through MAVS (Figure 5), which induces innate immunity by activating transcription factors IRF3 and IRF7, both of which increase type I interferon production [93]. Mouse cell-expressed TLR3 and TLR9, strongly induced by metronomic CPA, were identified by upstream regulator analysis as being involved in interferon response pathway activation (Figure 4).

Many other activated upstream regulators identified here (Tables 3 and 5) are also associated with anti-tumor immune responses. Examples include IL27, which promotes anti-tumor immunity [40], and growth hormone, which increases NK cell cytotoxicity to glioma cells [41]. Further, many of the inhibited upstream regulators identified (Tables 3 and 5) have strong pro-tumor activities (e.g., TGFB1, which increases glioma malignancy [49]), consistent with the overall strong anti-tumor responses that we have seen in the metronomic CPA-treated gliomas. However, not all of the gene expression changes induced by metronomic CPA are associated with beneficial responses. Select examples of undesirable tumor cells gene responses, shown in Table 1B, include the induction of CEACAM1, an interferon-inducible immune-inhibitory adhesion molecule [94], EREG, which induces glioma cell growth [95], and IDO1, an interferon-inducible immunosuppressive factor that is particularly active in glioma [96]. Undesirable responses involving upstream regulators of mouse genes were also observed, including activation of SAMSN1, which is associated with poor prognosis for survival in glioblastoma [62]. Further study is required to determine whether these are feedback inhibitory (compensatory) responses, and how they may impact the overall anti-tumor response to metronomic CPA treatment.

Recruitment of the innate immune system to metronomic CPA treated gliomas [12-14] is likely stimulated by tumor cell damage or stress response, with a critical level of DNA damage or cellular stress threshold being required to initiate a robust anti-tumor immune response, as suggested by the steep dose-response curve for metronomic CPA activation of an innate immune response in 9L gliomas [13]. Some of these effects are drug and tumor model dependent: 9L tumors do not begin to regress until the third cycle of every 6-day metronomic CPA treatment
[11,97], U251 tumors begin to regress immediately after the first CPA injection [12], and GL261 tumors regress around the time of the second treatment cycle $[12,15,16]$. Since the regression of these gliomas is at least in part dependent on innate immunity, these findings suggest that anti-tumor immunity is triggered by a different drugdependent kinetic of induced damage or stress in each tumor model. Several candidate pathways can be considered, including DNA damage, heat shock, cellular senescence, wounding and stress responses [98]. Specific examples include genes associated with oxidative stress (H2-M3, KLKR1, and TLR4; Additional file 1: Table S5A), retinoic acid (BMP4, CD38, MICB, IGFBP7, and KLF4; Additional file 1: Table S2A), and DNA damage response (p53 inducible protein Trp53inp1, Mgmt, Casp1, and Casp10; Additional file 1: Table S5A), all of which were induced by metronomic CPA treatment.

Metronomic CPA induced more than 30 genes important for induction of apoptosis, as seen in both human U251 tumor cells (human array), as well as in host cells of mice bearing U251 or 9L gliomas (mouse array) (Additional file 1: Tables S2A and S5A), consistent with our earlier finding that CPA kills 9L glioma cells by activating caspase 9-dependent apoptosis [99]. However, apoptosis-independent mechanisms of CPA-induced tumor cell death have been described, and may contribute to tumor regression [100]. Apoptosis-independent (necrotic) pathways that link macrophage-associated immunity to CPA-damaged tumors have been identified [100], and CPA-induced secretion of HMGB1 protein, a hallmark of immunogenic cell death [101] that may be a critical step in the activation of an anti-tumor immune response, independent of an intracellular apoptotic cascade $[69,102]$, has been reported $[90,100]$. Of note, the NK cell-associated receptor for HMGB1, Rage, was induced in the metronomic CPAtreated tumors (Figure $3 \mathrm{~B}$ and Figure $3 \mathrm{C}$ ). Metronomic CPA treatment also induced a core set of death-related genes that may be important for innate and/or adaptive immune activation by damaged tumor cells, including Sp110, Mx1, Mx2, Ebi3, Eomes, Tnfsf4, Gdf15, $D d x 58$, and $D h x 58$ (Figure 1A-C, Additional file 1: Tables S1 and S4 and Additional file 2: Figure S8B).

PPAR $\gamma$ expression was increased almost 5-fold in metronomic CPA-treated U251 tumor cells, and this could contribute to the responsiveness of these brain tumors to metronomic CPA. PPARy is linked to many apoptosis and interferon-related genes. In particular, IPA pathway analysis associated PPAR $\gamma$ with $C I D E C$, a known apoptosis inducer, and with STAT1, which is important for interferon and killer cell immune stimulation (Additional file 2: Figure S4C), as well as interleukin-4 and cathepsin $\mathrm{C}$ (Additional file 2: Figure S3). PEDF, which is strongly induced in metronomic CPA-treated 9L and U251 tumors [12], induces p53-mediated apoptosis through PPAR 
in HUVEC cells [103]. PPAR agonists increase the antiangiogenic activity of metronomic chemotherapy by upregulating endothelial cell expression of CD36, a receptor that binds thrombospondin-1 and initiates the extrinsic pathway of apoptosis [104]. Furthermore, combination of low-dose trofosfamide (a CPA derivative) with the PPAR antagonist pioglitazone and a COX-2 inhibitor resulted in tumor regression or tumor growth stasis and general improvements in patient outcome [104].

Many NK cell receptor ligands are up-regulated on the surface of cancer cells in response to cellular stresses, damage or other stimuli [98], which stimulate anti-tumor immunity when detected by NK cell surface receptors, such as NKG2D and NKp46 [98,105]. In accordance with our earlier qPCR data [12], the human DNA damage response NKG2D activating ligand $M I C B$ was significantly increased in U251 tumors at both early (day 12) and late (day 18) time points (Figure 1C). A second human DNA damage response NKG2D ligand, $U L B P 2$, was induced in the metronomic CPA-treated U251 tumors, but only at day 18, suggesting that MICB, and not ULBP2, contributes to the early onset of U251 tumor regression following metronomic CPA treatment. Mouse (host) microarray analysis showed a significant increase in the NK cell damage response receptor $C X C R 3$, which binds tumor-cell specific membrane-bound activation ligands CXCL9, CXCL10, and CXCL11 [106], all of which were also increased on the human array. Other immune-activating receptors increased by metronomic CPA treatment include pattern recognition receptors important for distinguishing self from nonself antigens, including toll-like receptors (human tumor cell-expressed TLR3 and TLR4, and mouse cell-expressed Tlrs 1, 4, 7, 8, and 13), MHC class I and class II receptors, as well as TLR-adaptor molecules, such as IRAK3 and TICAM2 (Additional file 2: Figure S8A). TLRs signal to the innate immune system to induce the death of inflamed and damaged cells [107]. Glia, neurons, and neural progenitor cells all express TLR2 and TLR4, and may contribute to the striking responsiveness of several glioma models to metronomic CPA-induced anti-tumor immunity seen in our studies. MHC class I receptors are normally expressed on all nucleated cells, however, they are most abundant on cytotoxic T and NK lymphocytes. MHC class II complexes are present on many immune cells, in particular antigenpresenting cells, such as innate immune macrophage and dendritic cells and adaptive immune B cells [108]. IPA network analysis showed a close association between interferons and MHC class I molecules, $\beta$-2-microglobulin and the antigen-processing molecule TAP (Additional file 2: Figure S8B). MHC and T-cell receptor complexes are also important for lymphocyte-mediated cytolysis via the granzyme-perforin pathway (Additional file 2: Figures S8B and S8C) [74]. While it is unclear from our array analyses which cells specifically express these receptor complexes, these complexes should be considered as possible mediators of metronomic CPA-induced anti-tumor immunity and tumor regression.

\section{Conclusions}

The mechanisms that govern the potent therapeutic responses to the intermittent metronomic CPA used here are only partially understood, but most likely involve immunogenic cell death $[69,70,109]$, which can stimulate dendritic cell and CD8-T cell-based immune responses leading to long-term immunity [16]. Tumors intrinsically sensitive to CPA cytotoxicity but unresponsive to metronomic CPA activation of anti-tumor immunity [27] likely undergo non-immunogenic apoptosis. While CPA and other drugs that activate immunogenic cell death are increasingly being studied in combination with immunotherapies $[10,110,111]$, there is a pressing need for rational, mechanistic approaches to determine optimal combinations, doses and schedules. The present identification of gene signatures of metronomic CPA responses and their upstream regulators will help elucidate underlying mechanisms and facilitate the development of clinically useful biomarkers of tumor responsiveness; such markers will ultimately be required for translation to the clinic to identify clinically effective metronomic regimens and responsive patients. The gene signatures of responsiveness include many genes known to be associated with innate immune cell recruitment and activation, as well as many novel factors whose role in the actions of metronomic CPA are poorly understood. Finally, our finding that metronomic CPA also induces the expression of factors that counter the tumor regression response, including several immunosuppressive factors, raises the possibility that such factors may contribute to tumor escape from CPA-induced, immune-based regression seen in some cases $[13,15]$, highlighting the need to identify the mechanisms involved and then develop effective mechanisms to circumvent them.

\section{Additional files}

\footnotetext{
Additional file 1: Comprised of one Excel workbook containing 8 Excel sheets, named Table S1 to Table S8, and provided in .xlsx format: Table S1. Detailed presentation of human microarray data for U251 tumors on metronomic CPA treatment days 12 and 18. Table S2. Annotation clusters for human U251 tumor genes up-regulated (Table S2A) or down-regulated (Table S2B) on CPA treatment days 12 and 18; relates to Table 2. Table S3. Upstream regulators of human U251 genes; relates to Table 3. Table S4. Detailed presentation of mouse microarray data for metronomic CPA-treated U251 and 9L tumors. Table S5. Annotation clusters of mouse genes up-regulated (Table S5A) or down-regulated (Table S5B) in U251 and 9L tumors; relates to Table 4. Table S6. Upstream regulators of differentially expressed mouse genes in metronomic CPA-treated U251 tumors that respond to metronomic CPA early. Table S7. Upstream regulators of differentially expressed mouse genes in metronomic CPA-treated U251 and $9 \mathrm{~L}$ tumors at late time points; relates to Table 5 .
} 
Additional file 2: Comprised of one pdf file containing Figures S1 to S8: Figure S1. Top network showing connections between metronomic CPA-induced expression of TNF and cell death-related genes, based on U251 tumor human genes increased by metronomic CPA (day 12). Figure S2. Upstream regulator mechanistic and downstream target pathway networks from upstream analysis, based on U251/human array, involving: A) Human IFNG and downstream STAT and NFkB signaling. B) Human IL27, an IPA-predicted upstream regulator. C) Mechanistic network for IL27 and interferon and NFkB signaling. Figure S3. PPARG gene network. Figure S4. Mouse gene upstream regulator analysis, based on U251 tumors (CPA treatment day 12). Downstream target networks for upstream regulators of responsive mouse genes: (A) IL12 complex, (B) mir-223, and (C) STAT1. Figure S5. Upstream regulator analysis of late-responding mouse genes, based on CPA-treatment of U251 tumors (day 18) and 9L tumors (day 24). Figure S6. Tumor cell activation of host innate immune system responses: A) Interferon secretion and downstream response gene pathways activated in damaged human U251 tumor cells. B) Innate immune stimulatory interleukin-15 production linked to interferon pathway activation and secretion. Figure $\mathbf{S 7}$. Canonical pathway related to host innate immune system responses to metronomic CPA-damaged tumor cells via complement component activation. Figure S8. Top networks involving A) tumor necrosis factor and DNA damage response genes, potentially leading to TLR or cytokine-based immune stimulation. B) Major histocompatibility complex and interferon pathway genes important for cell-to-cell signaling, immune activation, and targeted immune-mediated cell death. C) Perforin-granzyme cytolytic pathway, also related to $\mathrm{T}$ cell receptor (TCR) and $\mathrm{MHC}$ cell targeting.

\section{Abbreviations}

BW: Body weight; CPA: Cyclophosphamide; DNA: Deoxyribonucleic acid; DC: Dendritic cell; IPA: Ingenuity pathway analysis; MAP: Mitogen-activated protein; NK: Natural killer; MDSC: Myeloid-derived suppressor cell; PPAR: Peroxisome proliferator-activated receptor; TLR: Toll-like receptor.

\section{Competing interests}

The authors declare that they have no competing interests.

\section{Authors' contributions}

$J C D$ carried out animal studies and molecular analyses, and drafted the manuscript jointly with DJW. DJW and JCD jointly conceived the study, and DJW coordinated the overall project and revised and edited the manuscript Both authors read and approved the final manuscript.

\section{Acknowledgements}

Supported in part by NIH grant CA049248 (to DJW).

Received: 18 November 2014 Accepted: 23 April 2015 Published online: 08 May 2015

\section{References}

1. Browder T, Butterfield CE, Kraling BM, Shi B, Marshall B, O'Reilly MS, et al. Antiangiogenic scheduling of chemotherapy improves efficacy against experimental drug-resistant cancer. Cancer Res. 2000;60(7):1878-86.

2. Klement G, Baruchel S, Rak J, Man S, Clark K, Hicklin DJ, et al. Continuous low-dose therapy with vinblastine and VEGF receptor-2 antibody induces sustained tumor regression without overt toxicity. J Clin Invest. 2000;105(8):R15-24.

3. Pasquier $\mathrm{E}$, Kavallaris $\mathrm{M}$, Andre N. Metronomic chemotherapy: new rationale for new directions. Nat Rev Clin Oncol. 2010;7(8):455-65.

4. Hahnfeldt P, Hlatky L, Klement GL. Center of cancer systems biology second annual workshop-tumor metronomics: timing and dose level dynamics. Cancer Res. 2013;73(10):2949-54.

5. Lien K, Georgsdottir S, Sivanathan L, Chan K, Emmenegger U. Low-dose metronomic chemotherapy: a systematic literature analysis. Eur J Cancer. 2013:49(16):3387-95.

6. Penel N, Adenis A, Bocci G. Cyclophosphamide-based metronomic chemotherapy: after 10 years of experience, where do we stand and where are we going? Crit Rev Oncol Hematol. 2012;82(1):40-50.
7. Romiti A, Cox MC, Sarcina I, Di Rocco R, D'Antonio C, Barucca V, et al. Metronomic chemotherapy for cancer treatment: a decade of clinical studies. Cancer Chemother Pharmacol. 2013;72(1):13-33.

8. Kerbel RS, Kamen BA. The anti-angiogenic basis of metronomic chemotherapy. Nat Rev Cancer. 2004;4(6):423-36.

9. Bocci G, Nicolaou KC, Kerbel RS. Protracted low-dose effects on human endothelia cell proliferation and survival in vitro reveal a selective antiangiogenic window for various chemotherapeutic drugs. Cancer Res. 2002;62(23):6938-43.

10. Nars MS, Kaneno R. Immunomodulatory effects of low dose chemotherapy and perspectives of its combination with immunotherapy. Int J Cancer. 2013;132(11):2471-8.

11. Jounaidi Y, Waxman DJ. Frequent, moderate-dose cyclophosphamide administration improves the efficacy of cytochrome P-450/cytochrome P-450 reductase-based cancer gene therapy. Cancer Res. 2001;61(11):4437-44.

12. Doloff JC, Waxman DJ. VEGF receptor inhibitors block the ability of metronomically dosed cyclophosphamide to activate innate immunity-induced tumor regression. Cancer Res. 2012;72(5):1103-15.

13. Chen CS, Doloff JC, Waxman DJ. Intermittent metronomic drug schedule is essential for activating antitumor innate immunity and tumor xenograft regression. Neoplasia. 2014;16(1):84-96.

14. Doloff JC, Chen CS, Waxman DJ. Anti-tumor innate immunity activated by intermittent metronomic cyclophosphamide treatment of 9L brain tumor xenografts is preserved by anti-angiogenic drugs that spare VEGF receptor 2. Mol Cancer. 2014;13(1):158.

15. Wu J, Waxman DJ. Metronomic cyclophosphamide schedule-dependence of innate immune cell recruitment and tumor regression in an implanted glioma model. Cancer Lett. 2014;353(2):272-80.

16. Wu J, Waxman DJ. Metronomic cyclophosphamide eradicates large implanted GL261 gliomas by activating antitumor Cd8+ T-cell responses and immune memory. Oncolmmnology. 2015;4(4):e1005521. doi:10.1080/ $2162402 X .2015 .1005521$.

17. Balkwill F. Cancer and the chemokine network. Nat Rev Cancer. 2004;4(7):540-50.

18. Starnes T, Rasila KK, Robertson MJ, Brahmi Z, Dahl R, Christopherson K, et al. The chemokine CXCL14 (BRAK) stimulates activated NK cell migration: implications for the downregulation of CXCL14 in malignancy. Exp Hematol. 2006;34(8):1101-5.

19. Dewan MZ, Terunuma H, Ahmed S, Ohba K, Takada M, Tanaka Y, et al. Natural killer cells in breast cancer cell growth and metastasis in SCID mice. Biomed Pharmacother. 2005;59 Suppl 2:S375-9.

20. Ito M, Hiramatsu H, Kobayashi K, Suzue K, Kawahata M, Hioki K, et al. NOD/SCID/gamma(c)(null) mouse: an excellent recipient mouse model for engraftment of human cells. Blood. 2002;100(9):3175-82.

21. Li H, Han Y, Guo Q, Zhang M, Cao X. Cancer-expanded myeloid-derived suppressor cells induce anergy of NK cells through membrane-bound TGF-beta 1. J Immunol. 2009;182(1):240-9.

22. Banissi C, Ghiringhelli F, Chen L, Carpentier AF. Treg depletion with a low-dose metronomic temozolomide regimen in a rat glioma model. Cancer Immunol Immunother. 2009;58(10):1627-34.

23. Chen CA, Ho CM, Chang MC, Sun WZ, Chen YL, Chiang YC, et al. Metronomic chemotherapy enhances antitumor effects of cancer vaccine by depleting regulatory T lymphocytes and inhibiting tumor angiogenesis. Mol Ther. 2010;18(6):1233-43.

24. Ghiringhelli F, Menard C, Puig PE, Ladoire S, Roux S, Martin F, et al. Metronomic cyclophosphamide regimen selectively depletes CD4 + CD25+ regulatory $T$ cells and restores $T$ and NK effector functions in end stage cancer patients. Cancer Immunol Immunother. 2007:56(5):641-8.

25. Habu S, Fukui H, Shimamura K, Kasai M, Nagai Y, Okumura K, et al. In vivo effects of anti-asialo GM1. I. Reduction of NK activity and enhancement of transplanted tumor growth in nude mice. J Immunol. 1981;127(1):34-8.

26. Loven D, Hasnis E, Bertolini F, Shaked Y. Low-dose metronomic chemotherapy: from past experience to new paradigms in the treatment of cancer. Drug Discov Today. 2013;18(3-4):193-201.

27. Jia L, Waxman DJ. Thrombospondin-1 and pigment epithelium-derived factor enhance responsiveness of KM12 colon tumor to metronomic cyclophosphamide but have disparate effects on tumor metastasis. Cancer Lett. 2013;330(2):241-9.

28. Holloway MG, Miles GD, Dombkowski AA, Waxman DJ. Liver-specific hepatocyte nuclear factor-4alpha deficiency: greater impact on gene expression in male than in female mouse liver. Mol Endocrinol. 2008;22(5):1274-86 
29. Wauthier V, Sugathan A, Meyer RD, Dombkowski AA, Waxman DJ. Intrinsic sex differences in the early growth hormone responsiveness of sex-specific genes in mouse liver. Mol Endocrinol. 2010;24(3):667-78.

30. Weng L, Dai H, Zhan Y, He Y, Stepaniants SB, Bassett DE. Rosetta error model for gene expression analysis. Bioinformatics. 2006;22(9):1111-21.

31. Holloway MG, Laz EV, Waxman DJ. Codependence of growth hormoneresponsive, sexually dimorphic hepatic gene expression on signal transducer and activator of transcription $5 \mathrm{~b}$ and hepatic nuclear factor $4 a$ alpha. Mol Endocrinol. 2006;20(3):647-60.

32. Rajagopalan D. A comparison of statistical methods for analysis of high density oligonucleotide array data. Bioinformatics. 2003;19(12):1469-76.

33. Kent WJ. BLAT-the BLAST-like alignment tool. Genome Res. 2002;12(4):656-64

34. da Huang W, Sherman BT, Lempicki RA. Systematic and integrative analysis of large gene lists using DAVID bioinformatics resources. Nat Protoc. 2009;4(1):44-57

35. Kramer A, Green J, Pollard Jr J, Tugendreich S. Causal analysis approaches in Ingenuity Pathway Analysis. Bioinformatics. 2014;30(4):523-30.

36. Olofsson $M H$, Ueno $T$, Pan $Y, X u R$, Cai $F$, van der Kuip $H$, et al. Cytokeratin-18 is a useful serum biomarker for early determination of response of breast carcinomas to chemotherapy. Clin Cancer Res. 2007;13(11):3198-206.

37. Fu J, Yang QY, Sai K, Chen FR, Pang JC, Ng HK, et al. TGM2 inhibition attenuates ID1 expression in CD44-high glioma-initiating cells. Neuro Oncol. 2013;15(10):1353-65

38. Tomson BN, Arndt KM. The many roles of the conserved eukaryotic Paf1 complex in regulating transcription, histone modifications, and disease states. Biochim Biophys Acta. 2013;1829(1):116-26.

39. Koch M, May U, Kuhns S, Drechsler H, Adam N, Hattermann K, et al. Interleukin 27 induces differentiation of neural C6-precursor cells into astrocytes. Biochem Biophys Res Commun. 2007:364(3):483-7.

40. Natividad KD, Junankar SR, Mohd Redzwan N, Nair R, Wirasinha RC, King C, et al. Interleukin-27 signaling promotes immunity against endogenously arising murine tumors. PLoS One. 2013;8(3), e57469.

41. Shimizu K, Adachi K, Teramoto A. Growth hormone enhances natural killer cell activity against glioma. Journal of Nippon Medical School = Nippon Ika Daigaku zasshi. 2005;72(6):335-40

42. Oelmann E, Kraemer A, Serve H, Reufi B, Oberberg D, Patt S, et al. Autocrine interleukin-1 receptor antagonist can support malignant growth of glioblastoma by blocking growth-inhibiting autocrine loop of interleukin-1. Int J Cancer. 1997;71(6):1066-76.

43. Takano N, Sarfraz Y, Gilkes DM, Chaturvedi P, Xiang L, Suematsu M, et al. Decreased expression of cystathionine beta-synthase promotes glioma tumorigenesis. Mol Cancer Res. 2014;12(10):1398-406.

44. Chowdhury UR, Samant RS, Fodstad O, Shevde LA. Emerging role of nuclear protein 1 (NUPR1) in cancer biology. Cancer Metastasis Rev. 2009;28(1-2):225-32.

45. Guo C, Liu S, Sun MZ. Novel insight into the role of GAPDH playing in tumor. Clin Transl Oncol. 2013:15(3):167-72.

46. Speranza MC, Frattini V, Pisati F, Kapetis D, Porrati P, Eoli M, et al. NEDD9, a novel target of miR-145, increases the invasiveness of glioblastoma. Oncotarget. 2012;3(7):723-34.

47. Ajibade AA, Wang HY, Wang RF. Cell type-specific function of TAK1 in innate immune signaling. Trends Immunol. 2013;34(7):307-16.

48. DiDonato JA, Mercurio F, Karin M. NF-kappaB and the link between inflammation and cancer. Immunol Rev. 2012:246(1):379-400.

49. Kaminska B, Kocyk M, Kijewska M. TGF beta signaling and its role in glioma pathogenesis. Adv Exp Med Biol. 2013;986:171-87.

50. Ellis HP, Kurian KM. Biological Rationale for the Use of PPARgamma Agonists in Glioblastoma. Front Oncol. 2014:4:52.

51. Handschin C. Peroxisome proliferator-activated receptor-gamma coactivator-1alpha in muscle links metabolism to inflammation. Clin Exp Pharmacol Physiol. 2009;36(12):1139-43.

52. Guo D, Reinitz F, Youssef M, Hong C, Nathanson D, Akhavan D, et al. An LXR agonist promotes glioblastoma cell death through inhibition of an EGFR/ AKT/SREBP-1/LDLR-dependent pathway. Cancer discovery. 2011;1(5):442-56.

53. Lawrence T, Natoli G. Transcriptional regulation of macrophage polarization: enabling diversity with identity. Nat Rev Immunol. 2011;11(11):750-61.

54. Blacher E, Ben Baruch B, Levy A, Geva N, Green KD, Garneau-Tsodikova S, et al. Inhibition of glioma progression by a newly discovered CD38 inhibitor. Int J Cancer. 2014;136(6):1422-33.

55. Levy A, Blacher E, Vaknine H, Lund FE, Stein R, Mayo L. CD38 deficiency in the tumor microenvironment attenuates glioma progression and modulates features of tumor-associated microglia/macrophages. Neuro Oncol. 2012;14(8):1037-49.

56. Kito T, Kuroda E, Yokota A, Yamashita U. Cytotoxicity in glioma cells due to interleukin-12 and interleukin-18-stimulated macrophages mediated by interferon-gamma-regulated nitric oxide. J Neurosurg. 2003;98(2):385-92.

57. Mizesko MC, Banerjee PP, Monaco-Shawver L, Mace EM, Bernal WE, Sawalle-Belohradsky J, et al. Defective actin accumulation impairs human natural killer cell function in patients with dedicator of cytokinesis 8 deficiency. J Allergy Clin Immunol. 2013;131(3):840-8.

58. Yang L, Liu M, Gu Z, Chen J, Yan Y, Li J. Overexpression of SASH1 related to the decreased invasion ability of human glioma U251 cells. Tumour Biol. 2012;33(6):2255-63.

59. Mellor HR, Harris AL. The role of the hypoxia-inducible BH3-only proteins BNIP3 and BNIP3L in cancer. Cancer Metastasis Rev. 2007:26(3-4):553-66.

60. Zakrzewska A, Cui C, Stockhammer OW, Benard EL, Spaink HP, Meijer AH. Macrophage-specific gene functions in Spi1-directed innate immunity. Blood. 2010;116(3):e1-11.

61. Debatin KM, Krammer PH. Death receptors in chemotherapy and cancer. Oncogene. 2004;23(16):2950-66.

62. Yan Y, Zhang L, Xu T, Zhou J, Qin R, Chen C, et al. SAMSN1 is highly expressed and associated with a poor survival in glioblastoma multiforme. PLoS One. 2013;8(11), e81905

63. Zhu YX, Benn S, Li ZH, Wei E, Masih-Khan E, Trieu Y, et al. The SH3-SAM adaptor HACS1 is up-regulated in B cell activation signaling cascades. J Exp Med. 2004;200(6):737-47.

64. De Palma M, Lewis CE. Macrophage regulation of tumor responses to anticancer therapies. Cancer Cell. 2013;23(3):277-86.

65. Shultz SR, Tan XL, Wright DK, Liu SJ, Semple BD, Johnston L, et al. Granulocyte-macrophage colony-stimulating factor is neuroprotective in experimental traumatic brain injury. J Neurotrauma. 2014;31(10):976-83.

66. Zhang LH, Yin AA, Cheng JX, Huang HY, Li XM, Zhang YQ, et al. TRIM24 promotes glioma progression and enhances chemoresistance through activation of the PI3K/Akt signaling pathway. Oncogene. 2014;34(5):600-10.

67. Shurin MR, Naiditch $H$, Gutkin DW, Umansky V, Shurin GV. ChemolmmunoModulation: immune regulation by the antineoplastic chemotherapeutic agents. Curr Med Chem. 2012;19(12):1792-803.

68. Zitvogel L, Kepp O, Kroemer G. Immune parameters affecting the efficacy of chemotherapeutic regimens. Nat Rev Clin Oncol. 2011;8(3):151-60.

69. Inoue H, Tani K. Multimodal immunogenic cancer cell death as a consequence of anticancer cytotoxic treatments. Cell Death Differ. 2014;21(1):39-49.

70. Kono K, Mimura K, Kiessling R. Immunogenic tumor cell death induced by chemoradiotherapy: molecular mechanisms and a clinical translation. Cell Death \& Disease. 2013:4, e688.

71. Moschella F, Valentini M, Arico E, Macchia I, Sestili P, D'Urso MT, et al. Unraveling cancer chemoimmunotherapy mechanisms by gene and protein expression profiling of responses to cyclophosphamide. Cancer Res. 2011;71(10):3528-39.

72. Chakour R, Allenbach C, Desgranges F, Charmoy M, Mauel J, Garcia I, et al. A new function of the Fas-FasL pathway in macrophage activation. J Leukoc Biol. 2009;86(1):81-90.

73. Chu CY, Tseng J. Induction of Fas and Fas-ligand expression in plasmacytoma cells by a cytotoxic factor secreted by murine macrophages. J Biomed Sci. 2000:7(1):58-63.

74. Chavez-Galan L, Arenas-Del Angel MC, Zenteno E, Chavez R, Lascurain R. Cell death mechanisms induced by cytotoxic lymphocytes. Cell Mol Immunol. 2009;6(1):15-25.

75. Faure-Andre G, Vargas P, Yuseff Ml, Heuze M, Diaz J, Lankar D, et al. Regulation of dendritic cell migration by CD74, the MHC class II-associated invariant chain. Science. 2008;322(5908):1705-10.

76. Trapani JA, Smyth MJ. Functional significance of the perforin/granzyme cel death pathway. Nat Rev Immunol. 2002;2(10):735-47.

77. Palma JP, Aggarwal SK. Cisplatin and carboplatin mediated release of cytolytic factors in murine peritoneal macrophages in vitro. Anticancer Drugs. 1994;5(6):615-22.

78. Lindbom J, Ljungman AG, Tagesson C. Interferon gamma-induced gene expression of the novel secretory phospholipase A2 type IID in human monocyte-derived macrophages is inhibited by lipopolysaccharide. Inflammation. 2005:29(2-3):108-17.

79. Sasaki N, Higashi N, Taka T, Nakajima M, Irimura T. Cell surface localization of heparanase on macrophages regulates degradation of extracellular matrix heparan sulfate. J Immunol. 2004;172(6):3830-5. 
80. Sun JC, Beilke JN, Lanier LL. Adaptive immune features of natural killer cells. Nature. 2009;457(7229):557-61.

81. Jung MY, Park SY, Kim IS. Stabilin-2 is involved in lymphocyte adhesion to the hepatic sinusoidal endothelium via the interaction with alphaMbeta2 integrin. J Leukoc Biol. 2007;82(5):1156-65.

82. Seth S, Maier MK, Qiu Q, Ravens I, Kremmer E, Forster R, et al. The murine pan T cell marker CD96 is an adhesion receptor for CD155 and nectin-1. Biochem Biophys Res Commun. 2007;364(4):959-65.

83. George TC, Mason LH, Ortaldo JR, Kumar V, Bennett M. Positive recognition of MHC class I molecules by the Ly49D receptor of murine NK cells. J Immunol. 1999;162(4):2035-43.

84. Veillette A, Dong Z, Latour S. Consequence of the SLAM-SAP signaling pathway in innate-like and conventional lymphocytes. Immunity. 2007;27(5):698-710.

85. Shantsila E, Lip GY. The role of monocytes in thrombotic disorders. Insights from tissue factor, monocyte-platelet aggregates and novel mechanisms. Thromb Haemost. 2009;102(5):916-24.

86. Litvack ML, Palaniyar N. Review: Soluble innate immune pattern-recognition proteins for clearing dying cells and cellular components: implications on exacerbating or resolving inflammation. Innate Immun. 2010;16(3):191-200.

87. Lu JH, Teh BK, Wang L, Wang YN, Tan YS, Lai MC, et al. The classical and regulatory functions of $\mathrm{Clq}$ in immunity and autoimmunity. Cell Mol Immunol. 2008;5(1):9-21.

88. Cheon $\mathrm{H}$, Borden EC, Stark GR. Interferons and their stimulated genes in the tumor microenvironment. Semin Oncol. 2014;41(2):156-73.

89. Chawla-Sarkar M, Lindner DJ, Liu YF, Williams BR, Sen GC, Silverman RH, et al. Apoptosis and interferons: role of interferon-stimulated genes as mediators of apoptosis. Apoptosis. 2003;8(3):237-49.

90. Schiavoni G, Sistigu A, Valentini M, Mattei F, Sestili P, Spadaro F, et al. Cyclophosphamide synergizes with type I interferons through systemic dendritic cell reactivation and induction of immunogenic tumor apoptosis. Cancer Res. 2011;71(3):768-78.

91. Jiang F, Ramanathan A, Miller MT, Tang GQ, Gale Jr M, Patel SS, et al. Structural basis of RNA recognition and activation by innate immune receptor RIG-I. Nature. 2011;479(7373):423-7.

92. Balachandran S, Thomas E, Barber GN. A FADD-dependent innate immune mechanism in mammalian cells. Nature. 2004:432(7015):401-5.

93. Tang ED, Wang CY. MAVS self-association mediates antiviral innate immune signaling. J Virol. 2009;83(8):3420-8.

94. Markel G, Seidman R, Cohen Y, Besser MJ, Sinai TC, Treves AJ, et al. Dynamic expression of protective CEACAM1 on melanoma cells during specific immune attack. Immunology. 2009;126(2):186-200.

95. Auf G, Jabouille A, Delugin M, Guerit S, Pineau R, North S, et al. High epiregulin expression in human U87 glioma cells relies on IRE1alpha and promotes autocrine growth through EGF receptor. BMC Cancer. 2013;13:597.

96. Zhai L, Lauing KL, Chang AL, Dey M, Qian J, Cheng Y, et al. The role of IDO in brain tumor immunotherapy. J Neurooncol 2014. doi:10.1007/s11060-014-1687-8

97. Ma J, Waxman DJ. Modulation of the antitumor activity of metronomic cyclophosphamide by the angiogenesis inhibitor axitinib. Mol Cancer Ther. 2008;7(1):79-89.

98. Raulet DH, Guerra N. Oncogenic stress sensed by the immune system: role of natural killer cell receptors. Nat Rev Immunol. 2009;9(8):568-80.

99. Schwartz PS, Waxman DJ. Cyclophosphamide induces caspase 9-dependent apoptosis in 9L tumor cells. Mol Pharmacol. 2001:60(6):1268-79.

100. Guerriero JL, Ditsworth D, Fan Y, Zhao F, Crawford HC, Zong WX. Chemotherapy induces tumor clearance independent of apoptosis. Cancer Res. 2008;68(23):9595-600.

101. Tesniere A, Panaretakis T, Kepp O, Apetoh L, Ghiringhelli F, Zitvogel L, et al. Molecular characteristics of immunogenic cancer cell death. Cell Death Differ. 2008;15(1):3-12.

102. Yamazaki T, Hannani D, Poirier-Colame V, Ladoire S, Locher C, Sistigu A, et al. Defective immunogenic cell death of HMGB1-deficient tumors: compensatory therapy with TLR4 agonists. Cell Death Differ. 2014;21(1):69-78.

103. Ho TC, Chen SL, Yang YC, Liao CL, Cheng HC, Tsao YP. PEDF induces p53-mediated apoptosis through PPAR gamma signaling in human umbilical vein endothelial cells. Cardiovasc Res. 2007;76(2):213-23.

104. McCarty MF, Barroso-Aranda J, Contreras F. PPAR gamma agonists can be expected to potentiate the efficacy of metronomic chemotherapy through CD36 up-regulation. Med Hypotheses. 2008;70(2):419-23.

105. Gasser S, Orsulic S, Brown EJ, Raulet DH. The DNA damage pathway regulates innate immune system ligands of the NKG2D receptor. Nature. 2005;436(7054):1186-90.
106. Liu L, Callahan MK, Huang D, Ransohoff RM. Chemokine receptor CXCR3: an unexpected enigma. Curr Top Dev Biol. 2005;68:149-81.

107. Lin Q, Li M, Fang D, Fang J, Su SB. The essential roles of Toll-like receptor signaling pathways in sterile inflammatory diseases. Int Immunopharmacol. 2011;11(10):1422-32.

108. van den Hoorn T, Paul P, Jongsma ML, Neefjes J. Routes to manipulate MHC class II antigen presentation. Curr Opin Immunol. 2011;23(1):88-95.

109. Vacchelli E, Eggermont A, Sautes-Fridman C, Galon J, Zitvogel L, Kroemer G, et al. Trial Watch: Toll-like receptor agonists for cancer therapy. Oncoimmunology. 2013;2(8), e25238.

110. Andre N, Carre M, Pasquier E. Metronomics: towards personalized chemotherapy? Nat Rev Clin Oncol. 2014;11(7):413-31.

111. Sheng Sow H, Mattarollo SR. Combining low-dose or metronomic chemotherapy with anticancer vaccines: A therapeutic opportunity for lymphomas. Oncoimmunology. 2013;2(12), e27058.

112. Brezillon S, Pietraszek K, Maquart FX, Wegrowski Y. Lumican effects in the control of tumour progression and their links with metalloproteinases and integrins. FEBS J. 2013;280(10):2369-81.

113. Barbieri F, Pattarozzi A, Gatti M, Aiello C, Quintero A, Lunardi G, et al. Differential efficacy of SSTR1, -2 , and -5 agonists in the inhibition of $C 6$ glioma growth in nude mice. Am J Physiol Endocrinol Metab. 2009;297(5):E1078-88.

114. Wang BX, Rahbar R, Fish EN. Interferon: current status and future prospects in cancer therapy. J Interferon Cytokine Res. 2011;31(7):545-52.

115. Andzinski L, Wu CF, Lienenklaus S, Kroger A, Weiss S, Jablonska J. Delayed apoptosis of tumor associated neutrophils in the absence of endogenous IFN-beta. Int J Cancer J Int du Cancer. 2014:136(3):572-83.

116. Rebsamen M, Heinz LX, Meylan E, Michallet MC, Schroder K, Hofmann K, et al. DAI/ZBP1 recruits RIP1 and RIP3 through RIP homotypic interaction motifs to activate NF-kappaB. EMBO Rep. 2009;10(8):916-22.

117. Wang Z, Choi MK, Ban T, Yanai H, Negishi H, Lu Y, et al. Regulation of innate immune responses by DAI (DLM-1/ZBP1) and other DNA-sensing molecules. Proc Natl Acad Sci U S A. 2008;105(14):5477-82.

118. Takaoka A, Wang Z, Choi MK, Yanai H, Negishi H, Ban T, et al. DAI (DLM-1/ZBP1) is a cytosolic DNA sensor and an activator of innate immune response. Nature. 2007:448(7152):501-5

119. Hervouet E, Vallette FM, Cartron PF. Impact of the DNA methyltransferases expression on the methylation status of apoptosis-associated genes in glioblastoma multiforme. Cell Death Dis. 2010;1, e8.

120. Reich NC. A death-promoting role for ISG54/IFIT2. J Interferon Cytokine Res. 2013;33(4):199-205

121. Motomura K, Mittelbronn M, Paulus W, Brokinkel B, Keyvani K, Sure U, et al, DMBT1 homozygous deletion in diffuse astrocytomas is associated with unfavorable clinical outcome. J Neuropathol Exp Neurol. 2012;71(8):702-7.

122. Ellermeier J, Wei J, Duewell $P$, Hoves S, Stieg MR, Adunka T, et al. Therapeutic efficacy of bifunctional siRNA combining TGF-beta1 silencing with RIG-I activation in pancreatic cancer. Cancer Res. 2013;73(6):1709-20.

123. Gough MJ, Ruby CE, Redmond WL, Dhungel B, Brown A, Weinberg AD. OX40 agonist therapy enhances CD8 infiltration and decreases immune suppression in the tumor. Cancer Res. 2008;68(13):5206-15.

124. Bruyere C, Mijatovic T, Lonez C, Spiegl-Kreinecker S, Berger W, Kast RE, et al. Temozolomide-induced modification of the CXC chemokine network in experimental gliomas. Int J Oncol. 2011;38(5):1453-64.

125. Terasaki M, Sugita Y, Arakawa F, Okada Y, Ohshima K, Shigemori M. CXCL12/ CXCR4 signaling in malignant brain tumors: a potential pharmacological therapeutic target. Brain Tumor Pathol. 2011;28(2):89-97.

126. Ping YF, Yao XH, Jiang JY, Zhao LT, Yu SC, Jiang T, et al. The chemokine CXCL12 and its receptor CXCR4 promote glioma stem cell-mediated VEGF production and tumour angiogenesis via PI3K/AKT signalling. J Pathol. 2011;224(3):344-54.

127. Nakata S, Campos B, Bageritz J, Bermejo JL, Becker N, Engel F, et al. LGR5 is a marker of poor prognosis in glioblastoma and is required for survival of brain cancer stem-like cells. Brain Pathol. 2013;23(1):60-72.

128. Gales D, Clark C, Manne U, Samuel T. The Chemokine CXCL8 in Carcinogenesis and Drug Response. ISRN oncology. 2013;2013:859154

129. Leeman MF, Curran S, Murray Gl. The structure, regulation, and function of human matrix metalloproteinase-13. Crit Rev Biochem Mol Biol. 2002;37(3):149-66.

130. Kanao H, Enomoto T, Kimura T, Fujita M, Nakashima R, Ueda $Y$, et al. Overexpression of LAMP3/TSC403/DC-LAMP promotes metastasis in uterine cervical cancer. Cancer Res. 2005;65(19):8640-5.

131. Xia L, Huang W, Tian D, Chen Z, Zhang L, Li Y, et al. ACP5, a direct transcriptional target of FoxM1, promotes tumor metastasis and indicates poor prognosis in hepatocellular carcinoma. Oncogene. 2014;33(11):1395-406. 